(n)

\title{
Naringin protects cardiomyocytes against hyperglycemia-induced injuries in vitro and in vivo
}

\section{Qiong You1,*, Zijun Wu1,*, Bin Wu1', Chang Liu1, Ruina Huang1', Li Yang1', Runmin Guo1, Keng Wu $\mathbf{W}^{1}$ and Jingfu Chen ${ }^{2}$}

1Department of Cardiovasology, The Affiliated Hospital, Guangdong Medical College, Guangdong, Zhanjiang, China

2Department of Cardiology, The Third People's Hospital of Dongguan City, Cardiovascular Institute of Dongguan City, Dongguan, Guangdong, China

*(Q You and Z Wu contributed equally to this work)

\author{
Correspondence \\ should be addressed \\ to $\mathrm{K} \mathrm{Wu}$ or J Chen \\ Email \\ wukeng1245@hotmail.com \\ or chenjf-sums@hotmail.com
}

\begin{abstract}
We previously reported that naringin (NRG) protects cardiomyocytes against high glucose (HG)-induced injuries by inhibiting the MAPK pathway. The aim of this study was to test the hypothesis that NRG prevents cardiomyocytes from hyperglycemia-induced insult through the inhibition of the nuclear factor kappa B (NF- $\mathrm{KB}$ ) pathway and the upregulation of ATP-sensitive $\mathrm{K}^{+}\left(\mathrm{K}_{\mathrm{ATP}}\right)$ channels. Our results showed that exposure of cardiomyocytes to HG for $24 \mathrm{~h}$ markedly induced injuries, as evidenced by a decrease in cell viability and oxidative stress, and increases in apoptotic cells as well as the dissipation of mitochondrial membrane potential (MMP). These injuries were markedly attenuated by the pretreatment of cells with either NRG or pyrrolidine dithiocarbamate (PDTC) before exposure to HG. Furthermore, in streptozotocin (STZ)-induced diabetic rats and in HG-induced cardiomyocytes, the expression levels of caspase-3, bax and phosphorylated (p)-NF- $\kappa B$ p65 were increased. The increased protein levels were ameliorated by pretreatment with both NRG and PDTC. However, the expression levels of bcl-2 and $\mathrm{K}_{\text {ATP }}$ and superoxide dismutase (SOD) activity were decreased by hyperglycemia; the expression level of Nox4 and the ADP/ATP ratio were increased by hyperglycemia. These hyperglycemia-induced indexes were inhibited by the pretreatment of cardiomyocytes with NRG or PDTC. In addition, in STZ-induced diabetic rats, we also observed that NRG or PDTC contributed to protecting mitochondrial injury and myocardium damage. This study demonstrated that NRG protects cardiomyocytes against hyperglycemia-induced injury by upregulating $\mathrm{K}_{\text {ATP }}$ channels in vitro and inhibiting the NF-кB pathway in vivo and in vitro.
\end{abstract}

\section{Introduction}

Currently, statistical analysis shows that diabetes mellitus (DM) affects approximately 387 million people globally and is projected to increase two-fold in the next 25 years
(Huang et al. 2009). As a disease of epidemic proportions, DM damages every organ in the human body by causing serious microvascular and macrovascular diseases. 
Diabetic cardiomyopathy (DCM), one of the most prevalent cardiovascular complications and a major cause of death of DM, causes congestive heart failure (Lakdawala et al. 2013, Camafort 2015) and sudden death in young people (Ellis \& Di Salvo 2007). DCM is different from hypertensive cardiomyopathy and is a unique cardiovascular disease due to hyperglycemia-induced oxidative stress (Privratsky et al. 2003, Kamalakkannan \& Prince 2006, Saandeep et al . 2009, Murali et al. 2013, Peake et al. 2013, Umbarkar et al. 2015), inflammation (Marfella et al. 2003, Di et al. 2005, Venkatachalam et al. 2008), cardiac fibrosis (Fonarow \& Srikanthan 2006), myocardial apoptosis (Fonarow \& Srikanthan 2006) and mitochondrial damage (Boudina et al. 2007, Ceriello 2008).

The activation of nuclear factor kappa B (NF-kB), which can control the molecular processes within cardiomyocytes, contributes to many heart diseases, such as myocardial hypertrophy and coronary artery disease. Normally, NF- $\mathrm{kB}$ is an IкB (inhibitor of NF- $\mathrm{kB}$ )-bound complex in the cytoplasm and consists of homodimers or heterodimers mainly comprising the following subunits: RelA (p65), C-Rel, NF-кB1 (P50/P105), RelB and NF-кB2 (P52/P100). The NF-кB pathway may be activated by various stimuli, including growth factors, lymphokines, pharmacological agents, cytokines and stress. Upon stimulation, NF-кB is activated and released from its IкBbound complex and translocates into the nucleus from the cytoplasm. This molecular process allows NF- $\mathrm{KB}$ (p65) to bind to $\kappa B$ sequences and alter the expression of various target genes (Werner et al. 2005). The same pathophysiologic processes occur in hyperglycemiainduced cardiomyocyte injuries. An increase of NF- $\mathrm{kB}$ activity in high glucose (HG)-induced cardiomyocytes (Min et al. 2009, Tsai et al. 2012) and in streptozotocin (STZ)-induced diabetic rats (Chen et al. 2003, Mariappan et al. 2010) has been demonstrated. By binding to $\mathrm{\kappa B}$ sequences and altering the expression of various target genes, the NF-кB pathway is involved in related processes, including oxidative stress (Valen et al. 2001, Fang et al. 2004, Eisner et al. 2006), inflammation (Fang et al. 2004, Westermann et al. 2007a,b, Arkan \& Greten 2011), mitochondrial damage (Guleria et al. 2013), apoptosis (Guleria et al. 2013), endothelial dysfunction, hypertrophy and cardiac fibrosis (van Heerebeek et al. 2008) in DCM. Thus, NF-kB plays a key role in the development of DCM. However, the role of NF-кB in hyperglycemia-induced hypertrophy and cardiac fibrosis in the cardioprotective action of NRG remains unclear.

Another important molecule is the $\mathrm{K}_{\mathrm{ATP}}$ channel due to its cardioprotection in various types of cardiovascular diseases (Badalzadeh et al. 2014, 2015, Waza et al. 2014). In addition, accumulating evidence has revealed that DM has been associated with dysfunction of the cardiovascular $\mathrm{K}_{\text {ATP }}$ channels (Weintraub 2003). Hyperglycemia and DM impair vasodilation mediated by $\mathrm{K}_{\mathrm{ATP}}$ channels in human vascular smooth muscle cells (Miura et al. 2003, Kinoshita et al. 2004, Kinoshita et al. 2006). Furthermore, a recent study shows that diabetes reduces mitoK $_{\mathrm{ATP}}$ expression and function. These changes in mitoK $_{\text {ATP }}$ may provide an opportunity to understand the mechanisms that lead to DCM and the loss of cardioprotective mechanisms in the diabetic heart (Fancher et al. 2013). However, the roles of both sarcolemmal $\mathrm{K}_{\mathrm{ATP}}$ channels and mitochondrial $\mathrm{K}_{\text {ATP }}$ channels in HG-induced cardiomyocyte injury, particularly the cardioprotective role of NRG, remain unclear.

NRG is recognized by more and more people due to its comprehensive physiological and pharmacological effects, including antioxidant (Jung et al. 2003, Jeon et al. 2004, Rajadurai \& Prince 2007, Bodas et al. 2011, Jain \& Parmar 2011, Mahmoud et al. 2012), antihypercholesterolemic (Jung et al. 2003, Kim et al. 2004, Jung et al. 2006), anti-inflammatory (Jung et al. 2003, 2006, Bodas et al. 2011, Mahmoud et al. 2012), cardioprotection (Huang et al. 2013, Chen et al. 2014a,b) and anti-apoptotic effects (Jagetia et al. 2003, Kanno et al. 2003, 2004, Wu et al. 2013). Furthermore, Huang et al. (2013) and Chen et al. $(2014 a, b)$ demonstrated that NRG inhibited the MAPK pathway (p38 MAPK, ERK1/2 and JNK) in HG-induced injuries in H9c2 cardiac cells. In recent years, many studies have shown that NRG could regulate glycolipid metabolism. Our earlier report clarified that NRG could protect against cardiomyocyte dysfunction in diabetic hearts by inhibiting NF- $\mathrm{kB}$ (Wu et al. 2013). However, the underlying mechanisms are still unclear.

\section{Materials and methods}

\section{Chemicals}

Naringin (NRG), 5, 5', 6, $6^{\prime}$-tetrachloro-1, $1^{\prime}, 3,3^{\prime}$ tetraethyl-imidacarbocyanine iodide (JC-1), Hoechst 33258, STZ and pyrrolidine dithiocarbamate (PDTC, a specific inhibitor of NF- $\mathrm{kB}$ pathway) were purchased from Sigma-Aldrich. Diazoxide (DZ, a mitochondrial $\mathrm{K}_{\text {ATP }}$ channel opener), pinacidil (Pin, a non-selective $\mathrm{K}_{\text {ATP }}$ channel opener), 5-hydroxydecanoic acid (5-HD, a mitochondrial $\mathrm{K}_{\text {ATP }}$ channel blocker) and glibenclamide (Gli, a non-selective $\mathrm{K}_{\mathrm{ATP}}$ channel blocker) were

Published by Bioscientifica Ltd 
purchased from Cayman Chemical. The cell counter kit-8 (CCK-8) was supplied by Dojindo Lab (Kumamoto, Japan). Fetal bovine serum (FBS) and DMEM medium were obtained from Gibco BRL; anti-kir6.1 (R-14) was purchased from Santa Cruz Biotechnology; anti-pNF-kB p65 antibody, anti-p65 antibody anticaspase-3 antibody, anti-bax antibody and anti-bcl-2 antibody were purchased from Cell Signaling Technology; HRPconjugated secondary antibody and BCA protein assay kit were obtained from KangChen Bio-tech, Inc. (Shanghai, China). Enhanced chemiluminescence (ECL) solution was purchased from KeyGen Biotech (Nanjing, China).

\section{Experimental animals and treatment}

The experimental protocol was approved by the Institutional Animal Care and Ethical Committee of Guangdong Medical College (No: 01/022/12). Sixty male Sprague-Dawley (SD) rats weighing $200 \pm 10 \mathrm{~g}$ (7 weeks in age) were used in this experiment. Rats were housed under controlled temperature $\left(20 \pm 2^{\circ} \mathrm{C}\right)$ and lighting conditions (07:00 to 19:00 h, $12 \mathrm{~h}$ light:12 h darkness), with food and water available ad libitum. The high-sugar and high-fat diet comprised $66.6 \%$ basic rat chow, $20 \%$ sucrose, $10 \%$ lard, 3\% egg yolk and $0.4 \%$ cholesterol. Animals were randomly divided into six groups ( $n=10$ in each group): (i) the control group (healthy rats, $n=10$, mortality rate $0 \%$ ): the rats were given normal saline; (ii) the STZ group (healthy rats, $n=9$, mortality rate $10 \%$ ): the rats were fed a high-sugar and high-fat diet for 6 weeks and then were administered an intraperitoneal injection of $30 \mathrm{mg} / \mathrm{kg} / \mathrm{day}$ STZ; (iii) the STZ+low-dose NRG group (STZ+L-NRG, healthy rats, $n=9$, mortality rate $10 \%, \mathrm{NRG}=25 \mathrm{mg} / \mathrm{kg}$ ): the rats were fed a high-sugar and high-fat diet for 6 weeks and then were administered an intraperitoneal injection of $30 \mathrm{mg} / \mathrm{kg} /$ day STZ to establish the diabetic model, followed by an intraperitoneal injection of $25 \mathrm{mg} / \mathrm{kg} /$ day $\mathrm{NRG}$; (iv) the STZ + middle dose NRG group (STZ + M-NRG, healthy rats, $n=10$, mortality rate $0 \%, N R G=50 \mathrm{mg} / \mathrm{kg}$ ): the rats were fed a high-sugar and high-fat diet for 6 weeks and then were administered an intraperitoneal injection of $30 \mathrm{mg} / \mathrm{kg} /$ day STZ to establish the diabetic model, followed by an intraperitoneal injection of $50 \mathrm{mg} / \mathrm{kg} /$ day NRG; (v) the STZ+ high dose NRG group (STZ+H-NRG, healthy rats, $n=10$, mortality rate $0 \%, N R G=100 \mathrm{mg} / \mathrm{kg}$ ): the rats were fed a high-sugar and high-fat diet for 6 weeks and then were administered an intraperitoneal injection of $30 \mathrm{mg} / \mathrm{kg} /$ day STZ to establish the diabetic model, followed by an intraperitoneal injection of $100 \mathrm{mg} / \mathrm{kg} /$ day NRG; and (vi) the STZ+ PDTC group (healthy rats, $n=10$, mortality rate $0 \%$ ): the rats were fed a high-sugar and high-fat diet for 6 weeks and then were administered an intraperitoneal injection of $30 \mathrm{mg} / \mathrm{kg} /$ day STZ to establish the diabetic model, followed by an intraperitoneal injection of $100 \mathrm{mg} / \mathrm{kg} /$ day PDTC. After 6 weeks, the animals were killed (at the end of the experiments, the body weight of the various groups was recorded and the animals were anesthetized by $5 \%$ chloral hydrate) and the heart weight index determination of the ventricular myocardium was calculated. Concentration of the PDTC solution was $5 \mathrm{mg} / \mathrm{mL}$; concentration of the NRG solution was $2 \mu \mathrm{g} / \mathrm{mL}$ and concentration of the STZ solution was $10 \mathrm{mg} / \mathrm{mL}$. Our data showed that NRG (doses from 25 to $100 \mathrm{mg} / \mathrm{kg} /$ day) and $100 \mathrm{mg} / \mathrm{kg} /$ day PDTC were non-poisonous, and the data from the NRG group and PDTC group are not shown in this paper.

\section{H9c2 cardiac cells culture and treatment}

The H9c2 cardiac cells, a rat cardiac myoblasts cell line, were obtained from Sun Yat-sen University Experimental Animal Center (Guangzhou, Guangdong, China). The cells were grown in DMEM medium supplemented with $10 \%$ FBS under an atmosphere of $5 \% \mathrm{CO}_{2}$ at $37^{\circ} \mathrm{C}$ and 95\% air.

To investigate the role of NF- $\mathrm{KB}$ pathway and $\mathrm{K}_{\mathrm{ATP}}$ channels in HG-induced cardiomyocyte injury, H9c2 cells were preconditioned with $100 \mu \mathrm{M}$ PDTC (a specific inhibitor of NF-kB pathway) or $100 \mu \mathrm{M} \mathrm{DZ}$ or $50 \mu \mathrm{M}$ Pin for $30 \mathrm{~min}$ before exposure to $35 \mathrm{mM}$ glucose for $24 \mathrm{~h}$. To explore the protective effects of NRG on HG-induced injury, the H9c2 cells were preconditioned with $80 \mu \mathrm{M}$ NRG for $2 \mathrm{~h}$ before exposure to $35 \mathrm{mM}$ glucose for $24 \mathrm{~h}$. To further determine whether the protective effects of NRG were associated with the activation of $\mathrm{K}_{\mathrm{ATP}}$ channels, the cells were preconditioned with $100 \mu \mathrm{M} 5-\mathrm{HD}$ or $1 \mathrm{mM}$ Gli for $30 \mathrm{~min}$ before exposure to NRG treatment and $35 \mathrm{mM}$ glucose for $24 \mathrm{~h}$.

\section{Cell viability assay}

H9c2 cardiac cells were cultured in 96-well plates at a concentration of $1 \times 10^{4} / \mathrm{mL}$, the CCK- 8 assay was employed to measure the cell viability of $\mathrm{H} 9 \mathrm{c} 2$ cells. After the indicated treatments, $10 \mu \mathrm{L}$ of CCK- 8 solution at a 1/10 dilution was added to every well and then the plate was incubated for $3 \mathrm{~h}$ in the incubator. Absorbance at

Published by Bioscientifica Ltd 
$450 \mathrm{~nm}$ was measured with a microplate reader (Molecular Devices, Sunnyvale, CA, USA). The means of the optical density (OD) of 4 wells in the indicated groups were used to calculate the percentage of cell viability according to the following formula: cell viability $(\%)=(\mathrm{OD}$ treatment group/OD control group) $\times 100 \%$. The above experiment was repeated five times.

\section{Hoechst 33258 nuclear staining for assessment of apoptosis}

Apoptotic cell death was measured by the Hoechst 33258 staining followed by photofluorography. In brief, H9c2 cardiac cells were plated in $35 \mathrm{~mm}$ dishes at a density of $1 \times 10^{6}$ cells/well, the cells were preconditioned with $80 \mu \mathrm{M}$ NRG for $2 \mathrm{~h}$ or $100 \mu \mathrm{M}$ PDTC for $30 \mathrm{~min}$, and subsequently exposed to $35 \mathrm{mM}$ glucose for $24 \mathrm{~h}$. At the end of the different treatments, H9c2 cells were cultured with $4 \%$ paraformaldehyde in $0.1 \mathrm{~mol} / \mathrm{L}$ PBS ( $\mathrm{pH} 7.4$ ) for $10 \mathrm{~min}$. Then the slides were washed three times with PBS; after staining with $5 \mathrm{mg} / \mathrm{mL}$ Hoechst 33258 for $30 \mathrm{~min}$, H9c2 cells were washed three times with PBS, PBS was discarded and the cells were air dried. Finally, the cells were visualized under fluorescence microscope (BX50FLA, Olympus). Viable H9c2 cells displayed a uniform blue fluorescence throughout the nucleus and normal nuclear size; however, apoptotic H9c2 cells showed condensed, fractured or distorted nuclei. The experiment was repeated three times.

\section{Measurement of the mitochondrial membrane potential}

The mitochondrial membrane potential (MMP) was obtained using a fluorescent dye, JC-1, a cell-permeable cationic dye that preferentially enters mitochondria based on the highly negative MMP. Depolarization of MMP results in a loss of MMP from the mitochondria and a decrease in green fluorescence. H9c2 cells were cultured in a slide with DMEM at a density of $1 \times 10^{6}$ cells/well. After the indicated treatments, the slides were washed three times with PBS; then the cells were incubated with $1 \mathrm{mg} / \mathrm{L}$ $\mathrm{Rh} 123$ at $37^{\circ} \mathrm{C}$ for $30 \mathrm{~min}$ in the incubator, washed briefly three times with PBS and air-dried. Then fluorescence was measured over the hold field of vision by using fluorescent microscope connected to an imaging system (BX50-FLA). The mean fluorescence intensity (MFI) of JC-1 from three random fields was analyzed using the Image $1.47 \mathrm{i}$ software, the MFI was taken as an index of the levels of MMP. The experiment was repeated three times. http://joe.endocrinology-journals.org DOI: 10.1530/JOE-16-0004
(๑) 2016 Society for Endocrinology Printed in Great Britain
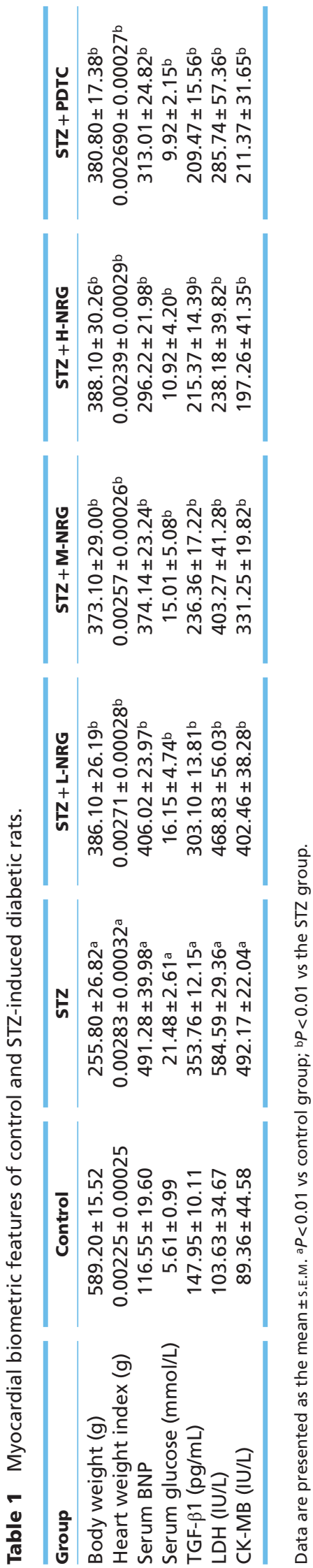

Published by Bioscientifica Ltd. 

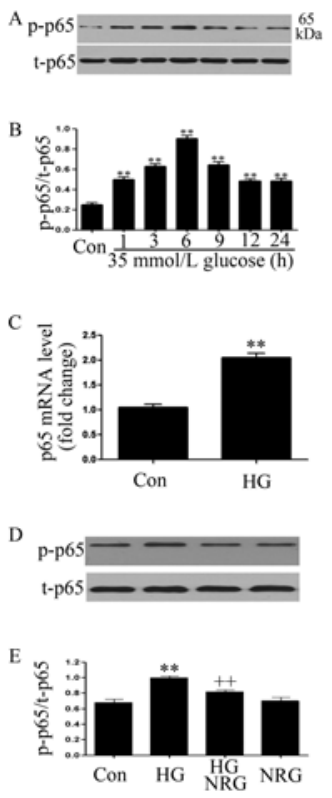

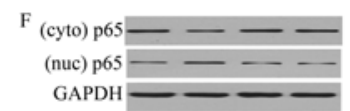

G
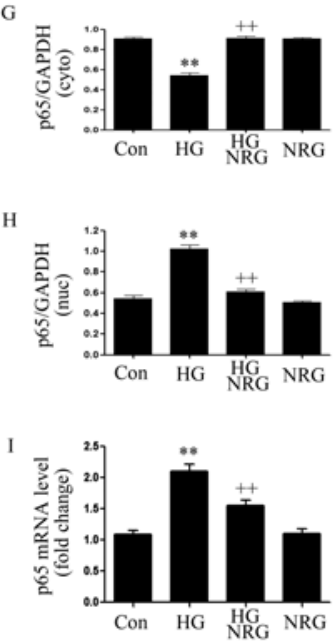
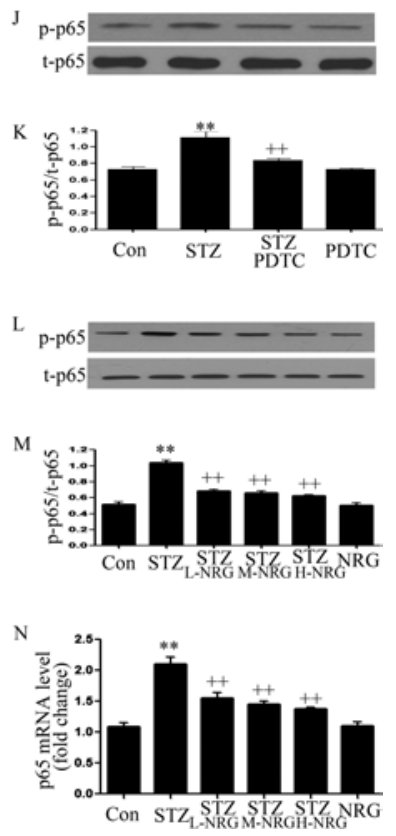

\section{Figure 1}

Naringin reduces hyperglycemia-induced activation of NF-KB p65 in $\mathrm{H} 9 \mathrm{c} 2$ cells and in STZ-induced diabetic rats. (A and B) H9c2 cells were exposed to $35 \mathrm{mM}$ glucose for the indicated times $(30,60,90,120,150$ and $180 \mathrm{~min})$ to test the effects of HG on NF-KB p65 phosphorylation, and then $\mathrm{H} 9 \mathrm{c} 2$ cells were exposed to $35 \mathrm{mM}$ glucose for $24 \mathrm{~h}$ in the absence or presence of pretreatment with $80 \mu \mathrm{M}$ NRG for $2 \mathrm{~h}$ before exposure to HG. Cytoplasm and nuclear extracts were extracted. The expression level of NF-кB p65 was also measured in STZ-induced diabetic rats. The expression of $\mathrm{p} 65$ was analyzed by Western blotting analysis. ( $B, C, E, G, H, K$ and $M$ ) Densitometric analysis of the KATP channels expression levels in (A, D, F, J and L) with Image J 1.47i software. ( $C, I$ and $N$ ) The p65 mRAN were tested. Data are shown as the mean \pm S.E.M. $(n=3)$. $\star * P<0.01$ vs with the control group; ${ }^{++} P<0.01$ vs with the HG-treated group and the STZ group, respectively. cyto, cytoplasm; HG, high glucose, $35 \mathrm{mM}$ glucose; NRG, naringin; nuc, nuclear.

\section{Western blot assay for expressions of protein}

After the indicated treatments, a small quantity of myocardial tissue of each group of rat was cut into fragments, and then homogenized with radioimmunoprecipitation assay (RIPA) buffer for protein extraction. Following the centrifugation of the lysates $\left(14,000 \boldsymbol{g}\right.$ for $15 \mathrm{~min}$ at $\left.4^{\circ} \mathrm{C}\right)$, the supernatants were quantified using a bicinchoninic acid protein assay. H9c2 cardiac cells were harvested and lysed with cell lysis solution at $4^{\circ} \mathrm{C}$ for $30 \mathrm{~min}$. The total proteins were quantified using the BCA protein assay kit. Loading buffer was added to cytosolic extracts; after boiling for about $5 \mathrm{~min}$, the same amounts of supernatant from each sample were fractionated by $10 \%$ SDS-PAGE; and then the total proteins were transferred into PVDF membranes. The membranes were blocked with 5\% fatfree milk for $60 \mathrm{~min}$ in fresh blocking buffer $(0.1 \%$ Tween 20 in TBS-T, and incubated with anticaspase- 3 antibody (1:1000 dilution), anti-bcl-2 antibody (1:1000 dilution), anti-bax antibody (1:1000 dilution), anti-p65 antibody (1:1000 dilution), anti-p-NF-кB antibody (1:1000 dilution) and anti-Nox4 antibody (1:1000 dilution) in freshly prepared TBS-T with 3\% free-fat milk overnight with gentle agitation at $4^{\circ} \mathrm{C}$. Membranes were washed for three times with TBS-T and successively incubated with horseradish peroxidase (HRP)-conjugated goat antirabbit secondary antibody (1:2500 dilution) in TBS-T with $3 \%$ fat-free milk for $90 \mathrm{~min}$ at room temperature. Then the membranes were washed three times with TBS-T for $5 \mathrm{~min}$. The immunoreactive signals were subsequently visualized by using enhanced chemiluminescence (ECL) detection. In order to quantify the protein expression, the X-ray films were scanned and analyzed with ImageJ $1.47 \mathrm{i}$ software. The experiment was repeated three times.

\section{Real-time PCR}

Real-time PCR was carried out in $200 \mu \mathrm{L}$ Eppendorf (EP) tubes without bacteria and enzyme. Approximately $2 \mu \mathrm{g}$ cell total RNA, $1 \mu \mathrm{L}$ oligo duplicated $\mathrm{T}, 1 \mu \mathrm{L}$ diethylnitrophenyl thiophosphate and diethylpyrocarbonate liquid were placed into PCR system for reaction at $65^{\circ} \mathrm{C}$ for $5 \mathrm{~min}$. Once the reaction ended, the liquid was taken out and put on ice. Then $4 \mu \mathrm{L} 5 \times$ first strand buffer and $2 \mu \mathrm{L}$ DL-dithiothreitol were successively added for reaction at $37^{\circ} \mathrm{C}$ for $2 \mathrm{~min}$; after that $1 \mu \mathrm{L}$ reverse transcriptase was added to every tube for reaction at $37^{\circ} \mathrm{C}$ for $50 \mathrm{~min}$ and then at $70^{\circ} \mathrm{C}$ for $15 \mathrm{~min}$.

\section{Examination of intracellular reactive oxygen species generation}

Intracellular reactive oxygen species (ROS) generation was tested by the oxidative conversion of cell-permeable oxidation of $2^{\prime}, 7^{\prime}$-dichlorodihydrofluorescein diacetate (DCFH-DA) to fluorescent DCF. H9c2 cells were cultured in a slide. With the different treatments, the slides were washed three times; $10 \mu \mathrm{M}$ DCFH-DA solution in
() 2016 Society for Endocrinology Printed in Great Britain 
A

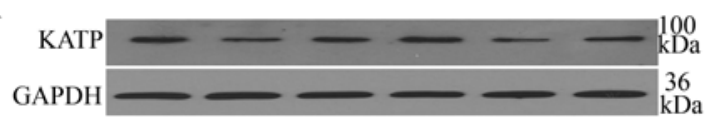

B
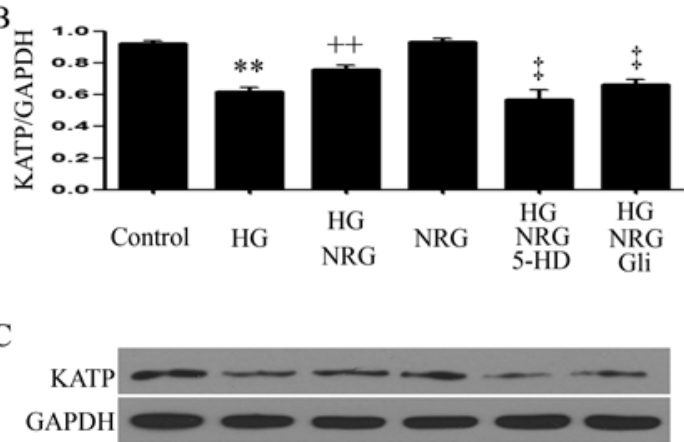

D

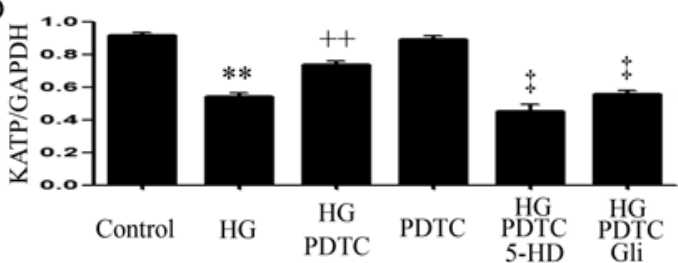

E

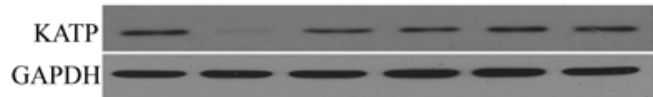

F

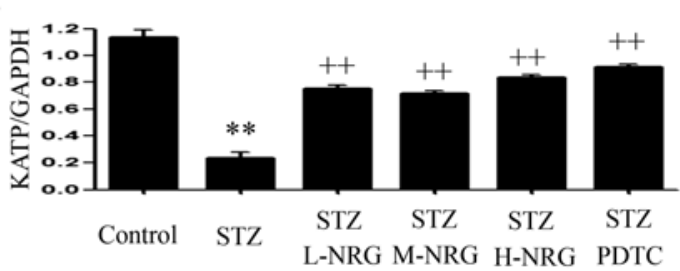

G

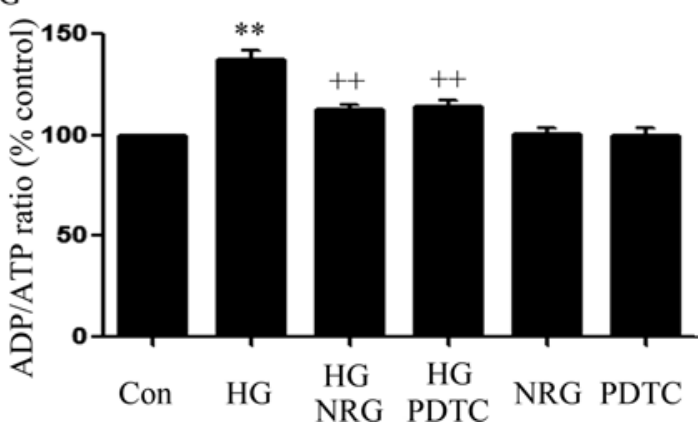

Figure 2

NRG and PDTC reduce the hyperglycemia-induced decrease in the expression level of ATP-sensitive potassium (KATP) channel protein in vitro and in vivo. (A C and E) KATP channel protein expression levels were semi-quantified by Western blotting analysis. (A, B, C and D). The cells were treated with $35 \mathrm{mM}$ glucose for $24 \mathrm{~h}$ with or without preconditioned with $80 \mu \mathrm{M}$ NRG for $2 \mathrm{~h}$ or $100 \mu \mathrm{M}$ PDTC or $100 \mu \mathrm{M}$ diazoxide (DZ) or $50 \mu \mathrm{M}$ pinacidil (Pin) or $100 \mu \mathrm{M}$ 5-hydroxydecanoic acid (5-HD) or $1 \mathrm{mM}$ glibenclamide (Gli) for $30 \mathrm{~min}$. (E and F). The SD rats were treated with or without $30 \mathrm{mg} / \mathrm{kg} / \mathrm{day}$ STZ or 25,50 or $100 \mathrm{mg} / \mathrm{kg} /$ day NRG or $100 \mathrm{mg} / \mathrm{kg} /$ day PDTC. (B, D and F) Densitometric analysis of the KATP channels expression levels in (A) and (C). (G) The ratio of ADP/ATP was assessed using Bradbury method. Data are shown as the mean \pm s.E.M. $(n=3)$. ** $P<0.01$ vs control (Con) group; $++P<0.01$ vs the HG group or the STZ group, ${ }^{\ddagger} P$ vs the HG + NRG group or HG + PDTC group.

serum-free medium was added to the slides, and then $\mathrm{H} 9 \mathrm{c} 2$ cells were incubated at $37^{\circ} \mathrm{C}$ for $30 \mathrm{~min}$ in the incubator. The slides were washed five times with PBS, and DCF fluorescence was measured over the entire field of vision using a fluorescence microscope connected to an imaging system (BX50-FLA). The MFI of ROS from five random fields was measured using ImageJ $1.47 \mathrm{i}$ software and the MFI was used as an index of the amount of ROS. The experiment was repeated three times.

\section{Measurement of SOD activity}

Superoxide dismutase (SOD) activity was tested by using SOD assay kit. After the indicated treatments, cells were washed using PBS and lysed in ice-cold 0.1 M Tris- $\mathrm{HCl}(\mathrm{pH}$ 7.4) containing $0.5 \%$ Triton, $5 \mathrm{mM} \beta$-mercaptoethanol and $0.1 \mathrm{mg} / \mathrm{mL}$ phenylmethylsulfonyl fluoride. Lysates were clarified by centrifugation at $14,000 \boldsymbol{g}$ at $4^{\circ} \mathrm{C}$ for 5 min and cell debris was discarded. SOD activity was detected using a commercial 'SOD Assay Kit' according to the manufacturer's protocol (Sigma). Absorbance values at $450 \mathrm{~nm}$ were measured using a microplate reader. The experiment was repeated three times.

\section{Serum cardiac markers}

At the end of experimental period, rats were anesthetized with diethyl ether. Blood was collected by retro-orbital puncture and then the serum was separated. Serum levels of creatine kinase-MB isoenzyme (CK-MB) and lactate dehydrogenase (LDH) enzymes were measured by automated chemistry analyzer (Microlab 300, Merck) using reagent kits. Values of $\mathrm{LDH}$ and CK-MB were expressed in international units per liter (IU/L).

\section{ELISA for detection of IL-1 $\beta$, IL- 6 and TNF- $\alpha$ in culture supernatant}

H9c2 cells were cultured in 96-well plates. After the different indicated treatments, the levels of interleukin (IL)-1 $\beta$, IL-6 and TNF- $\alpha$ in the culture media were tested

Published by Bioscientifica Ltd. 
A

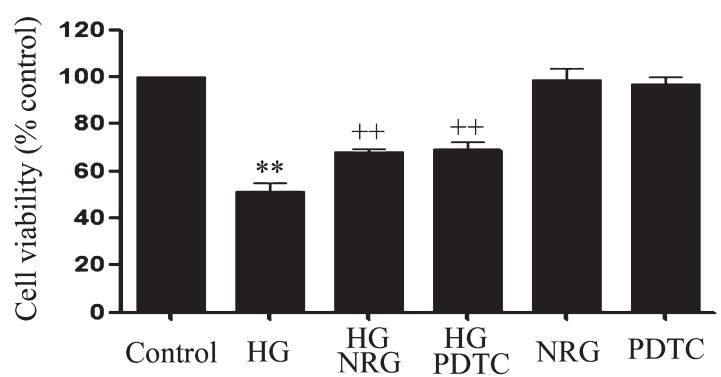

$\mathrm{B}$

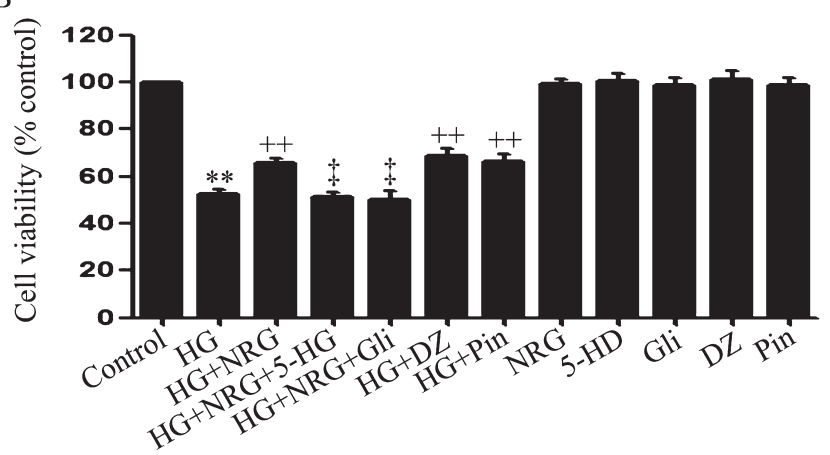

Figure 3

Naringin and PDTC alleviate HG-induced cardiomyocyte cytotoxicity in H9c2 cardiac cells. The cells were treated with $35 \mathrm{mM}$ glucose for $24 \mathrm{~h}$ with or without preconditioned with $80 \mu \mathrm{M}$ NRG or $100 \mu \mathrm{M}$ PDTC or $100 \mu \mathrm{M}$ diazoxide (DZ) or $50 \mu \mathrm{M}$ pinacidil (Pin) or $100 \mu \mathrm{M}$ 5-hydroxydecanoic acid (5-HD) or $1 \mathrm{mM}$ glibenclamide (Gli) for $30 \mathrm{~min}$. Cell viability was measured by the cell counter kit (CCK-8) assay. Data are shown as the mean \pm S.E.M. $(n=5) . * * P<0.01$ vs with the control group; $++P<0.01$ vs with the HG group, ${ }^{+} P<0.01$ vs with the $\mathrm{HG}+\mathrm{NRG}$ group; $\mathrm{HG}$ high glucose, $35 \mathrm{mM}$ glucose; NRG, naringin; PDTC, pyrrolidine dithiocarbamate, a specific inhibitor of NF-kB pathway.

by ELISA according to the manufacturer's instruction. The experiments were repeated five times.

\section{Assay of ATP and ADP}

ATP was measured based on bioluminescence generated from luciferin-luciferase reaction. The following reaction results in the generation of measurable light at a wavelength of $562 \mathrm{~nm}$ :

$$
\begin{aligned}
& \mathrm{ATP}+\text { luciferin }+\mathrm{O}_{2}^{\text {luciferase }} \text { oxyluciferin }+ \text { AMP } \\
& +\mathrm{PP}+\mathrm{CO}+\text { light }(562 \mathrm{~nm})
\end{aligned}
$$

Both intracellular ATP and ADP measurements were performed on $\mathrm{H} 9 \mathrm{c} 2$ cardiac cells using the standard curve of ATP. Light emission was measured with a Sirius tube luminometer, Berthold Defection Systems (Germany). After calibration against the ATP standard, the ATP content of the cell lysate was determined. Then, ATP/ADP ratio was calculated.
In brief, the cells were pelleted in a microcentrifuge tube by centrifugation at $3000 \boldsymbol{g}$ for $10 \mathrm{~min}$. The cellular ATP was lysated by adding $0.5 \mathrm{~mL}$ water and boiling the cell pellet for $5 \mathrm{~min}$. The sample was then vortexed and centrifuged $\left(3000 \mathrm{~g}\right.$ for $5 \mathrm{~min}$ at $\left.4^{\circ} \mathrm{C}\right), 12 \mu \mathrm{L}$ supernatant was used for bioluminescence measurement. About $12 \mu \mathrm{L}$ of the supernatant was added to $25 \mu \mathrm{L}$ cocktail (luciferin and $\mathrm{Mg}$ ) and $10 \mu \mathrm{L}$ of Tris buffer; $5 \mu \mathrm{L}$ luciferase enzyme was added to the mixture and luminescence was read at $562 \mathrm{~nm}$. Luminescence intensity correlated to ATP level in hepatocytes. For total ATP measurement, $12 \mu \mathrm{L}$ supernatant was added to $5 \mu \mathrm{L} \mathrm{MgCl}_{2}$ and $5 \mu \mathrm{L}$ phosphoenolpyruvate and $12 \mu \mathrm{L}$ phosphokinase. Phosphokinase changed the ADP to ATP. The mixture was incubated for $2 \mathrm{~min}$ and then $25 \mu \mathrm{L}$ cocktail (luciferin and $\mathrm{Mg}$ ) and $5 \mu \mathrm{L}$ luciferase were added to the mixture and consequently luminescence was read at $562 \mathrm{~nm}$. ADP level was calculated by calculating the difference between total ATP and primary ATP.

\section{Histopathology}

The tissues were from the left ventricle. After killing the rats, their hearts were fixed in $4 \%$ formaldehyde, embedded in paraffin and sectioned. Sections were stained with hematoxylin and eosin (H\&E) and examined with microscope, and photographic images were captured.

\section{Transmission electron microscopy}

The tissues were from the left ventricle. Following the commencement of the experiment, selected samples of heart tissues from rats of each group were perfused with $0.9 \% \mathrm{NaCl}$ at $37^{\circ} \mathrm{C}$, and mixed with paraformaldehyde and $4 \%$ glutaraldehyde at $4^{\circ} \mathrm{C}$. Then the samples were minced into small pieces $(\sim 2 \mathrm{~mm})$ and successively fixed in $2.5 \%$ glutaraldehyde in $0.1 \mathrm{~mol} / \mathrm{L}$ sodium cacodylate buffer ( $\mathrm{pH} 7.3$ ) for $2 \mathrm{~h}$. The specimens were then rinsed in buffer, postfixed in cacodylate-buffered $2 \% \mathrm{OsO}_{4}$, stained in uranyl acetate, dehydrated gradiently in ethanol and embedded in epoxy resin by standard procedures. Finally, 50-70 nm superthin slices were obtained. The thin sections were stained with uranyl acetate and lead citrate and examined with a Philips TECNA10 electron microscope, and the photographic images were captured.

\section{Statistical analysis}

All data are presented as mean \pm s.E.M. Differences between groups were analyzed by one-way (ANOVA by using

Published by Bioscientifica Ltd 
A Hoechst 33258 staining
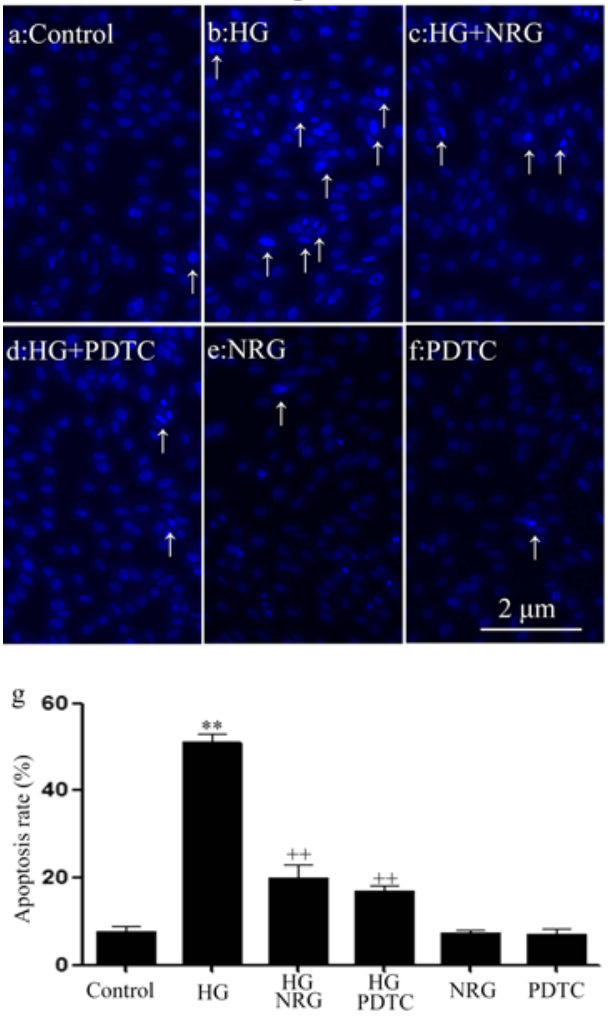

B Western blot
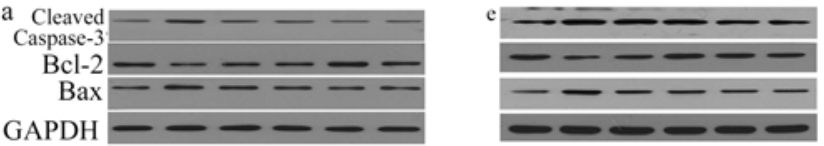

b
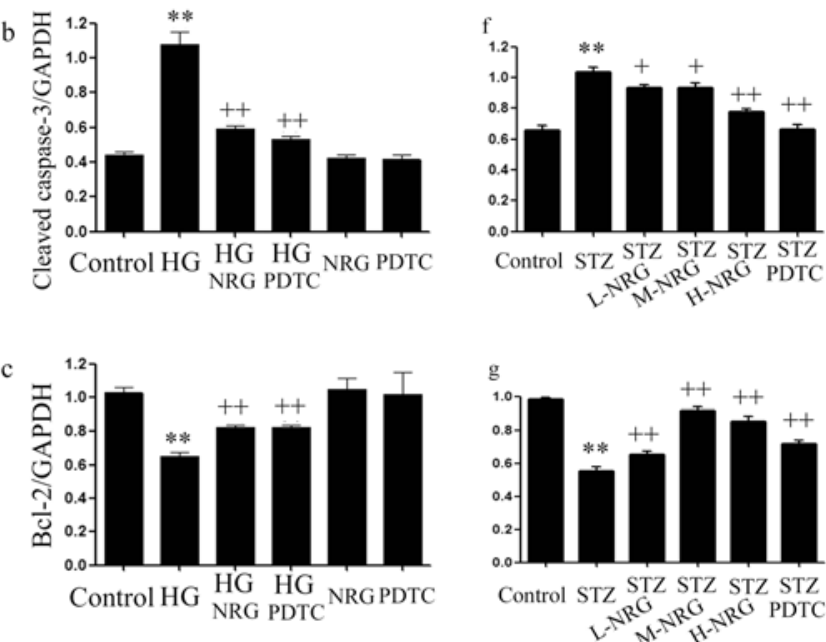

d

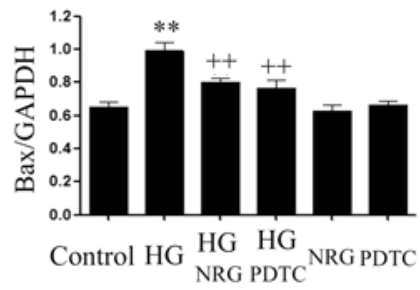

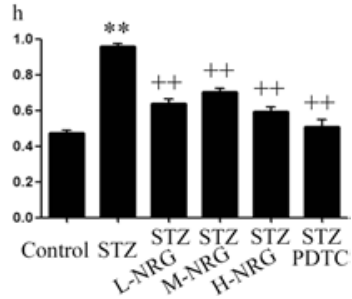

Figure 4

Role of KATP channels and NF- $\mathrm{KB}$ pathway in the protective effect of NRG against the hyperglycemia-induced cardiomyocyte apoptosis in vitro and in vivo. (A) Hoechst 33258 nuclear stating followed by fluorescence imaging was performed to test cell apoptosis. (B) The expression levels of cleaved caspase-3, bax and bcl-2 were semi-quantified by Western blotting assay. (A-a) Control group. (A-b) H9c2 cells were exposed to $35 \mathrm{mM}$ glucose for $24 \mathrm{~h}$. (A-c) H9c2 cells precondition with $80 \mu \mathrm{M}$ NRG for $2 \mathrm{~h}$ before exposure to HG for $24 \mathrm{~h}$. (A-d) H9c2 cells precondition with $100 \mu \mathrm{M}$ PDTC for 30 min before exposure to $\mathrm{HG}$ for $24 \mathrm{~h}$. (A-e) H9c2 cells precondition with $80 \mu \mathrm{M}$ NRG for $2 \mathrm{~h}$. (A-f) H9c2 cells pre-treated with $100 \mu \mathrm{M}$ PDTC for $30 \mathrm{~min}$. (A-g) The apoptotic rate was analyzed with a cell counter of the Image J 1.47i software. (B-b, C, d, $f, g$ and h) The data in (B-a and e) was quantified by densitometric analysis with Image J 1.47 i software. Data are shown as the mean \pm S.E.M. $(n=3)$. ${ }^{*} P<0.01$ vs with the control group; $+P<0.05,++P<0.01$ vs with the HG group. HG, high glucose, $35 \mathrm{mmol} / \mathrm{L}$ glucose; NRG, naringin; PDTC, pyrrolidine dithiocarbamate, a specific inhibitor of NF-kB pathway. White arrow: the abbreviation for nucleus.

SPSS 13.0 (SPSS) software, and followed by LSD post hoc comparison test. A value of $P<0.05$ was considered to be significant.

\section{Results}

\section{General features of control and diabetic rats}

Diabetic rats displayed a significantly reduced body weight and heart weight index associated with hyperglycemia compared with control rats. Diabetes also exerted an effect on the serum B-type natriuretic peptide (BNP) and transforming growth factor (TGF)- $\beta 1$ levels.
The fasting blood glucose level was markedly elevated in STZ-induced diabetic rats. The diabetes-induced changes in biometrics were significantly changed by NRG and PDTC treatment. All these results are shown in Table 1.

\section{NRG attenuates the hyperglycemia-induced expression of NF- $\mathrm{KB}$ p65 in vitro and in vivo}

First, we observed the effects of $\mathrm{HG}$ ( $35 \mathrm{mM}$ glucose) on NF- $\kappa$ B p65 phosphorylation (p) in vitro. H9c2 cells were exposed to $\mathrm{HG}$ for the indicated times $(30,60$, $90,120,150$ and $180 \mathrm{~min}$ ), and the expression level of p-NF-кB p65 (p-p65) was significantly upregulated, 
A DCFH-DA staining
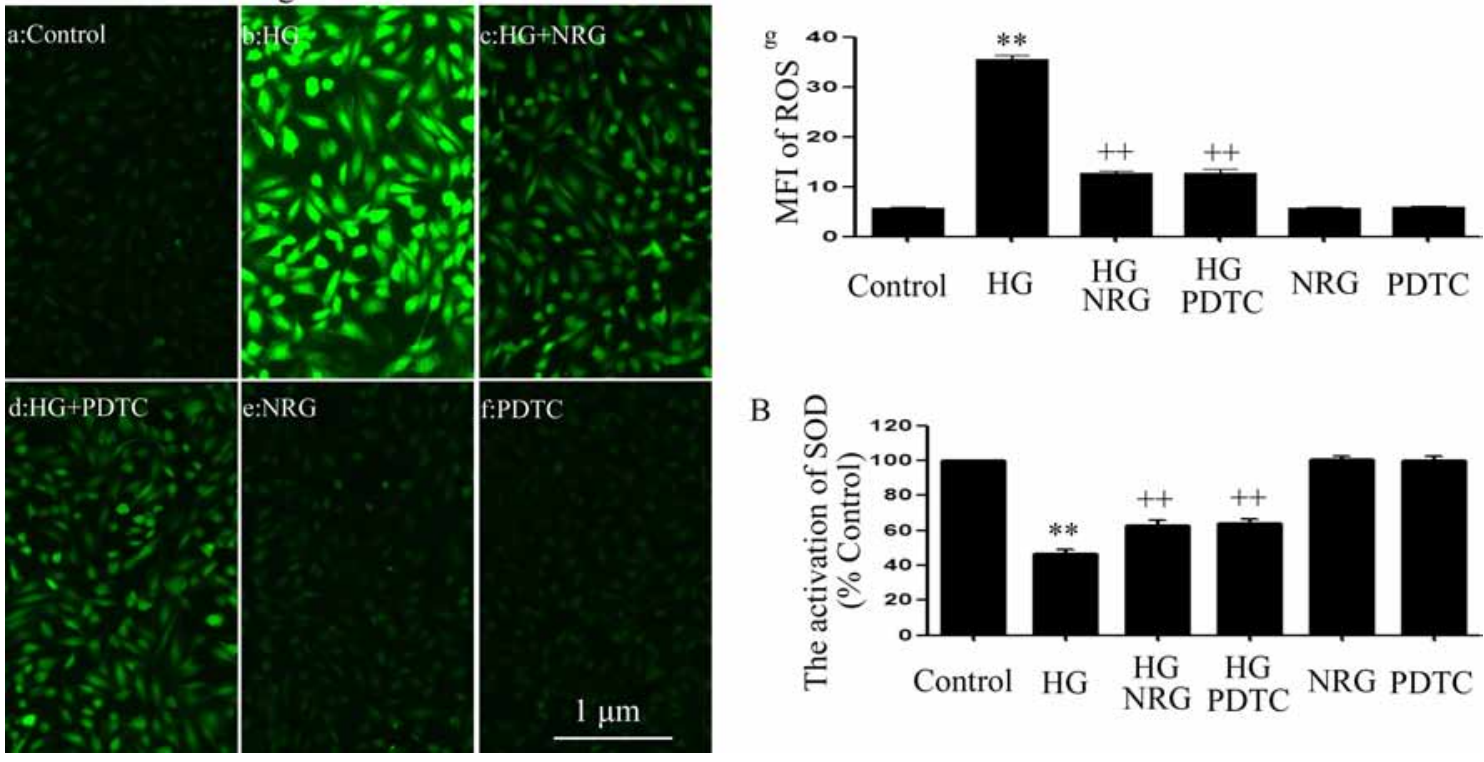

B

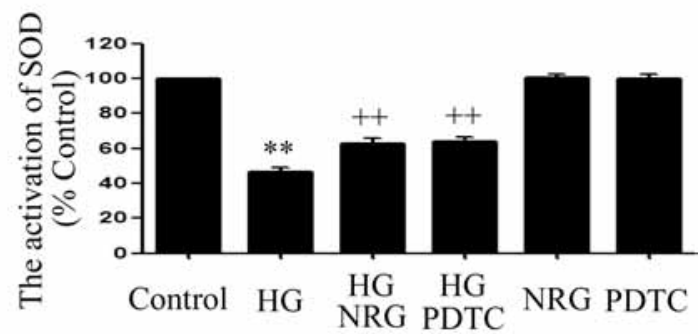

Figure 5

Naringin and PDTC alleviate HG-induced increased ROS generation increase HG-induced decreased SOD activity in H9c2 cells. A-a to b: Amplification factor: 100x. (A) DCFH-DA staining followed by photofluorography to measure intracellular ROS level. (B) SOD activity was tested by using superoxide dismutase (SOD) assay kit. (Aa) Control group. (A-b) H9c2 cells were exposed to $35 \mathrm{mM}$ glucose for $24 \mathrm{~h}$. (A-c) H9c2 cells were precondition with $80 \mu \mathrm{M}$ NRG for $2 \mathrm{~h}$ before HG for $24 \mathrm{~h}$. (A-d) H9c2 cells were precondition with $100 \mu \mathrm{M}$ PDTC for 30 min before exposure to HG for $24 \mathrm{~h}$. (A-d) H9c2 cells were precondition with $80 \mu \mathrm{M}$ NRG for $2 \mathrm{~h}$. (A-f) H9c2 cells were pre-treated with $100 \mu \mathrm{M}$ PDTC for $30 \mathrm{~min}$. (A-g) Quantitative analysis for the mean fluorescence intensity (MFI) of DCFH-DA in (A-a to e) with the imageJ 1.47i software. Data are shown as the mean \pm S.E.M. $(n=3) . * * P<0.01$ vs with the control group; $++P<0.01$ vs with the HG group. HG, high glucose; NRG, naringin; PDTC, pyrrolidine dithiocarbamate, a specific inhibitor of NF-kB pathway.

reaching a peak at 90 min (Fig. $1 \mathrm{~A}$ and $\mathrm{B}$ ), while the total (t)-p65 expression was unchanged. The HG-induced p65 mRNA level was increased. Then, we tested the nuclear translocation of t-p65, as shown in Fig. 1E, F and G, and the expression level of total t-p65 in the cell nucleus was greater than in the cell cytoplasm, which suggested that NF- $\mathrm{kB}$ was activated and translocated to the nucleus from the cytoplasm in HG-induced cardiomyocytes.

Second, we tested the influence of NRG on the HG-induced activation of the NF-kB pathway. H9c2 cardiac cells were pretreated with $80 \mu \mathrm{M}$ NRG for $2 \mathrm{~h}$ before exposure to HG for $24 \mathrm{~h}$. As shown in Fig. $1 \mathrm{C}$ and D, the increased expression of p-p65 was significantly reduced by NRG pretreatment. Alone, NRG did not alter the basal expression level of p-p65 in H9c2 cells. Subsequently, we explored the effect of NRG on the nuclear translocation of the NF-kB p65 subunit. NRG pretreatment significantly ameliorated the HG-induced nuclear translocation (Fig. 1E and G), with increasing amounts of NF-kB p65 in the cytosol (Fig. 1E and F). Furthermore, we found that NRG inhibited the p65 mRNA level. These results suggested that NRG inhibited NF-kB activation by blocking the HG-induced phosphorylation and nuclear translocation of p65 subunit.
In STZ-induced diabetic rats, the expression levels of p-p65 and p65 mRNA were markedly increased. The treatment of STZ-induced diabetic rats with NRG (L-NRG, M-NRG and H-NRG) or PDTC also markedly suppressed the STZ-induced increased expression level of p-p65 and the p65 mRNA level (Fig. 1H, I, J and K).

\section{NRG and PDTC attenuate the hyperglycemia-induced decreased expression of the $\mathrm{K}_{\text {ATP }}$ channel protein in vitro and in vivo}

As indicated in Fig. 2A, B, C and D, H9c2 cells were exposed to $35 \mathrm{mM}$ glucose for $12 \mathrm{~h}$, and the expression level of the $\mathrm{K}_{\text {ATP }}$ channel protein was obviously reduced. Importantly, the decreased expression of the $\mathrm{K}_{\text {ATP }}$ channel was ameliorated by the pretreatment of the cells with $80 \mu \mathrm{M}$ NRG for $2 \mathrm{~h}$ or $100 \mu \mathrm{M}$ PDTC for $30 \mathrm{~min}$ before exposure to HG for $12 \mathrm{~h}$. However, the basal expression level of the $\mathrm{K}_{\mathrm{ATP}}$ channel was not changed by separate treatment with $80 \mu \mathrm{M}$ NRG for $2 \mathrm{~h}$ or $100 \mu \mathrm{M}$ PDTC for $30 \mathrm{~min}$. It was shown that the blockade of $\mathrm{K}_{\mathrm{ATP}}$ channels with 5-HD or Gli markedly reversed the increased effect of NRG and PDTC against 

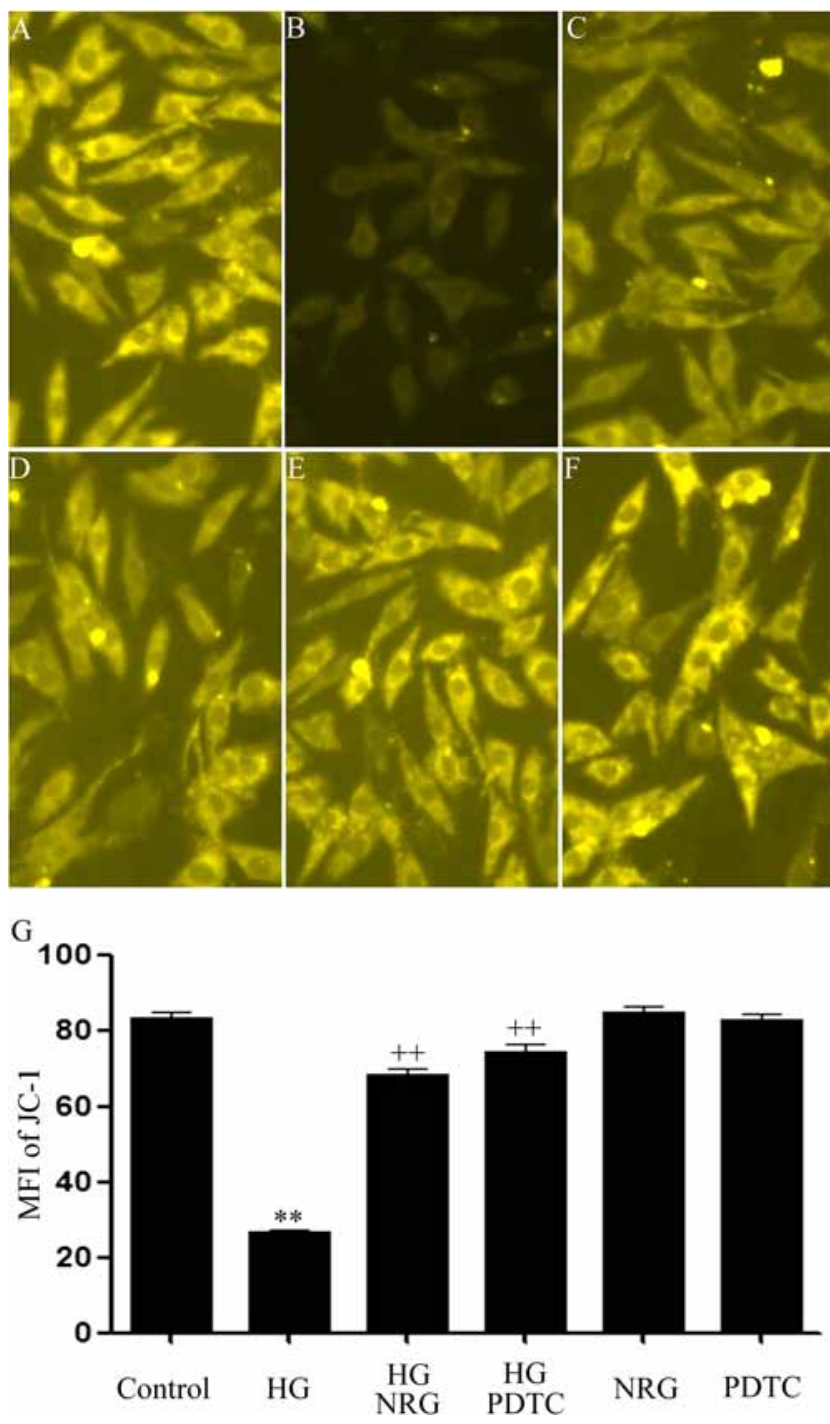

Figure 6

Naringin and PDTC block HG-induced dissipation of MMP in H9c2 cells. (A, B, C, D, E and F) After the indicated treatments, MMP was tested by Rh123 staining followed by photofluorography. (A) Control group. (B) $\mathrm{H} 9 \mathrm{c} 2$ cells were exposed to $35 \mathrm{mmol} / \mathrm{L}$ glucose for $24 \mathrm{~h}$. (C) H9c2 cells precondition with $80 \mu \mathrm{M}$ naringin for $2 \mathrm{~h}$ before HG for $24 \mathrm{~h}$. (D) H9c2 cells precondition with $100 \mu \mathrm{M}$ PDTC for $30 \mathrm{~min}$ before exposure to HG for $24 \mathrm{~h}$. (E) H9c2 cells precondition with $80 \mu \mathrm{M}$ naringin for $2 \mathrm{~h}$. (F) H9c2 cells pre-treated with $100 \mu \mathrm{M}$ PDTC for $30 \mathrm{~min}$. (G) Quantitative analysis for the mean fluorescence (MFI) of Rh123 in (A, B, C, D, E and F) with the imageJ $1.47 \mathrm{i}$ software. Data are shown as the mean \pm S.E.M. $(n=3)$. $* * P<0.01$ vs with the control group; ${ }^{++} P<0.01$ vs with the HG-treated group. NRG, naringin; PDTC, pyrrolidine dithiocarbamate, a specific inhibitor of NF-kB pathway.

the HG-induced decreased expression of $\mathrm{K}_{\mathrm{ATP}}$ channel proteins (Fig. 2B). Similarly, compared with the control group, the expression level of the $\mathrm{K}_{\mathrm{ATP}}$ channel protein was obviously reduced in STZ-induced diabetic rats. However, the STZ-induced decreased expression level of $\mathrm{K}_{\mathrm{ATP}}$ channel proteins increased to different degrees in the STZ+L-NRG group, STZ+M-NRG group, $\mathrm{STZ}+\mathrm{H}-\mathrm{NRG}$ group and STZ+PDTC group. These data indicated that NRG and PDTC alleviated the decrease in the expression level of $\mathrm{K}_{\mathrm{ATP}}$ channels induced by $\mathrm{HG}$ in $\mathrm{H} 9 \mathrm{c} 2$ cardiac cells.

Furthermore, we observed the effects of HG (35 mM glucose) on the ADP/ATP ratio in vitro. $\mathrm{H} 9 \mathrm{c} 2$ cells were exposed to HG for $2 \mathrm{~h}$, and the ADP/ATP ratio was significantly upregulated (Fig. 2G). However, the upregulated ADP/ATP ratio was markedly repressed by pretreatment with $80 \mu \mathrm{M}$ NRG for $2 \mathrm{~h}$ or $100 \mu \mathrm{M}$ PDTC for 30 min before exposure to HG. Alone, NRG or PDTC did not affect the ADP/ATP ratio of H9c2 cardiac cells.

The NF-KB pathway and $K_{A T P}$ channels are involved in the protective effect of NRG against HG-induced cardiomyocyte cytotoxicity in $\mathrm{H} 9 \mathrm{c} 2$ cardiac cells

As shown in Fig. 3A, the exposure of $\mathrm{H} 9 \mathrm{c} 2$ cells to $\mathrm{HG}$ for $24 \mathrm{~h}$ obviously induced cytotoxicity, which led to a decrease in cell viability. However, the decreased cell viability was markedly repressed by pretreatment with $80 \mu \mathrm{M}$ NRG for $2 \mathrm{~h}$ or $100 \mu \mathrm{M}$ PDTC for $30 \mathrm{~min}$ before exposure to HG. Alone, NRG or PDTC did not affect the viability of H9c2 cardiac cells.

To explore the role of $\mathrm{K}_{\mathrm{ATP}}$ channels in HG-induced cytotoxicity, the cells were treated with $100 \mu \mathrm{M} \mathrm{DZ}$ or $50 \mu \mathrm{M}$ Pin for $30 \mathrm{~min}$ before exposure to HG. As shown in Fig. 3B, pretreatment of H9c2 cardiac cells with DZ or Pin considerably mitigated the HG-induced cytotoxicity, as evidenced by an increase in cell viability. To further investigate the role of $\mathrm{K}_{\mathrm{ATP}}$ channels in the protective effect of NRG against HG-induced cytotoxicity, the cells were treated with $100 \mu \mathrm{M} 5$-HD or $1 \mathrm{mM}$ Gli for 30 min before exposure to NRG and HG. It was shown that the blockade of $\mathrm{K}_{\mathrm{ATP}}$ channels with 5-HD or Gli markedly reversed the protective effect of NRG against the HG-induced cytotoxicity, which resulted in a decrease in cell viability (Fig. 3B). Alone, 5-HD or Gli did not significantly alter the cell viability. These data suggested that $\mathrm{K}_{\text {ATP }}$ channels mediated the anticytotoxicity of NRG in the HG-treated H9c2 cardiac cells.

\section{NRG and PDTC suppress hyperglycemia-induced cardiomyocyte apoptosis in vitro and in vivo}

In Fig. 4A-b and g, exposure of H9c2 cells to $35 \mathrm{mM}$ glucose for $24 \mathrm{~h}$ induced typical apoptosis, which was manifested

Published by Bioscientifica Ltd. 
A

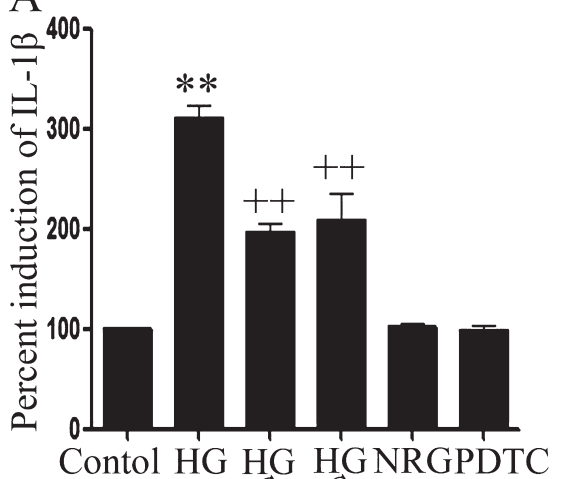
TRG

$\mathrm{C}$

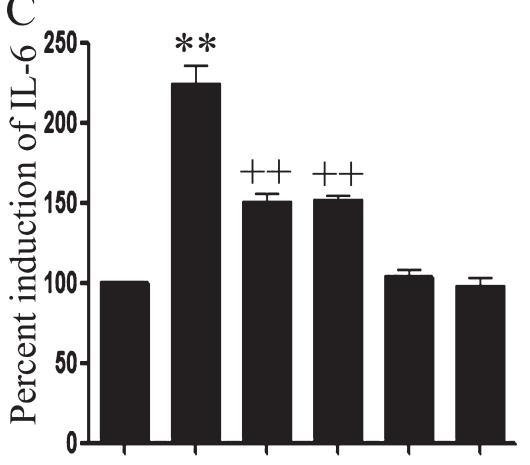

ControlHG HG HGNRG PDTC

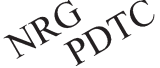

$\mathrm{E}$

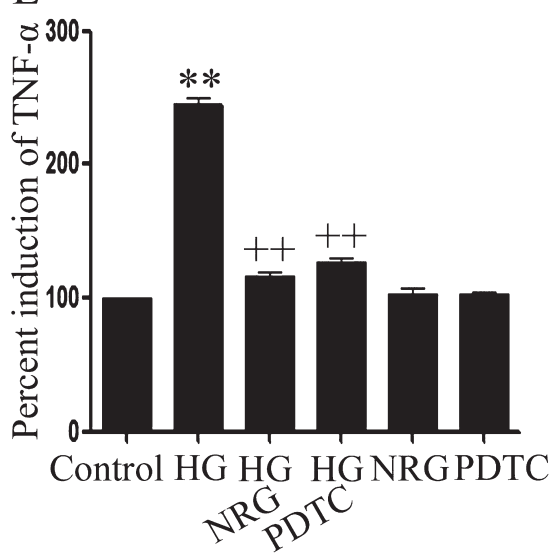

$\mathrm{B}$

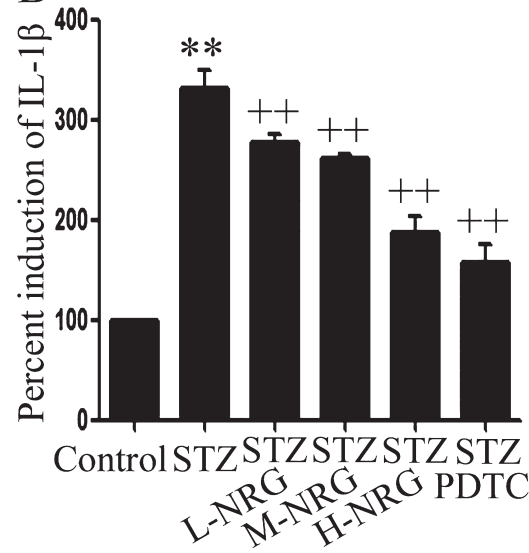

D

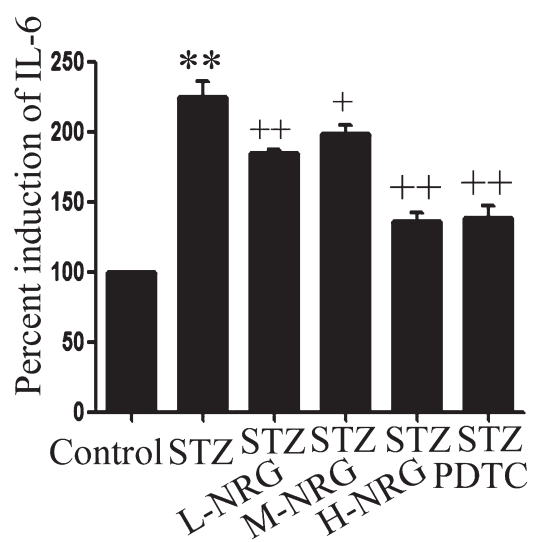

$\mathrm{F}$

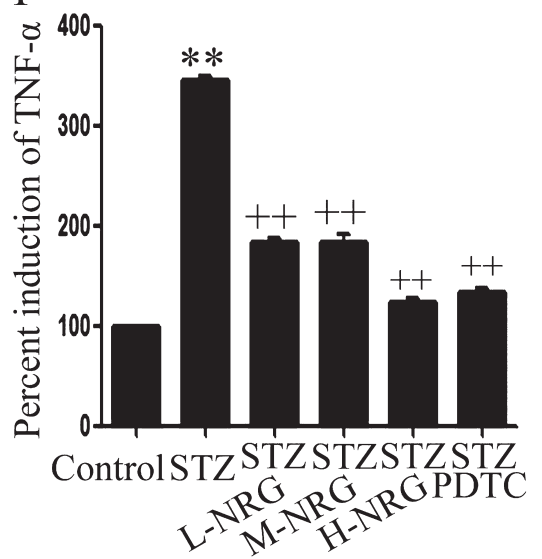

Figure 7

Naringin and PDTC alleviate hyperglycemiainduced production of interleukin (IL)-1 $1 \beta$, IL- 6 and tumor necrosis factor- $\alpha$ (TNF- $\alpha$ ) in vitro and in vivo. The cells were treated with $35 \mathrm{mM}$ glucose for $24 \mathrm{~h}$ with or without preconditioned with $80 \mu \mathrm{M}$ NRG for $2 \mathrm{~h}$ or $100 \mu \mathrm{M}$ PDTC. The SD rats were treated with or without $30 \mathrm{mg} / \mathrm{kg} / \mathrm{day}$ STZ or 25,50 or $100 \mathrm{mg} / \mathrm{kg} /$ day NRG or $100 \mathrm{mg} /$ $\mathrm{kg} /$ day PDTC. Enzyme-linked immunosorbent assay (ELISA) was performed to determine the levels of (A and B) IL-1 $\beta$, (C and D) IL-6, and ( $E$ and F) TNF- $\alpha$ in cell supernatants. Data are shown as the mean \pm S.E.M. $(n=5) . * * P<0.01$ vs the control (Con) group; $++P<0.01$ vs the HG-treated group. as the nuclear condensation and fragmentation condensation of chromatin and the shrinkage of nuclei and apoptotic bodies. However, pretreatment of the cells with $80 \mu \mathrm{M}$ NRG for $2 \mathrm{~h}$ of $\mathrm{HG}$ exposure obviously mitigated the HG-induced increase in the number of cells that underwent apoptosis (Fig. 4A-c and d). In addition, preconditioning of the cells with $100 \mu \mathrm{M}$
PDTC for 30 min before exposure to HG also ameliorated HG-induced apoptosis of cardiac cells (Fig. 4A-d and g). Alone, NRG (Fig. 4A-e and g) or PDTC (Fig. 4A-f and g) did not significantly change the number of apoptotic $\mathrm{H} 9 \mathrm{c} 2$ cells. Similarly, both in HG-induced H9c2 cardiac cells and in STZ-induced rats, the expression levels of cleaved caspase- 3 and bax were markedly enhanced, and 
$200 X$
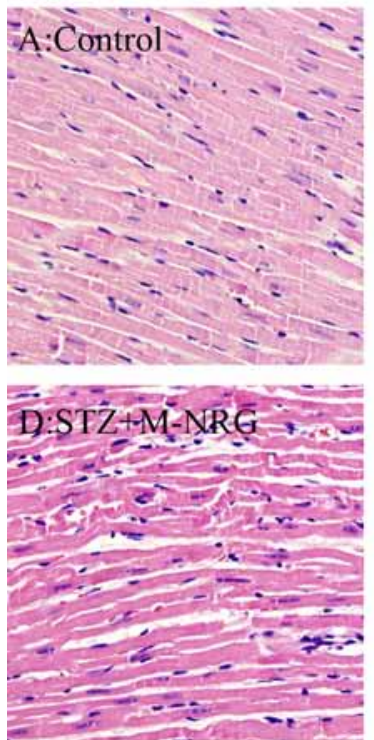

$400 \mathrm{X}$
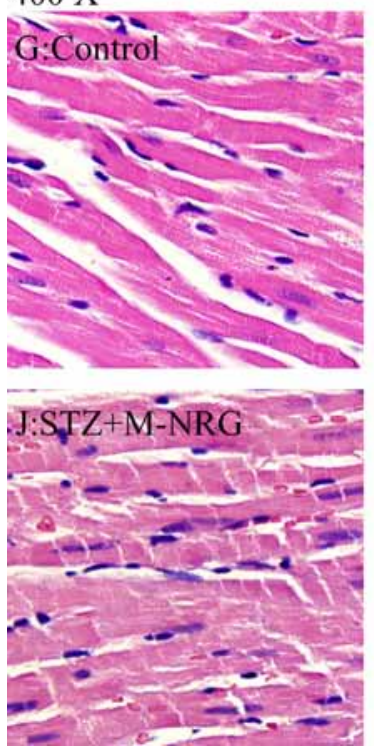
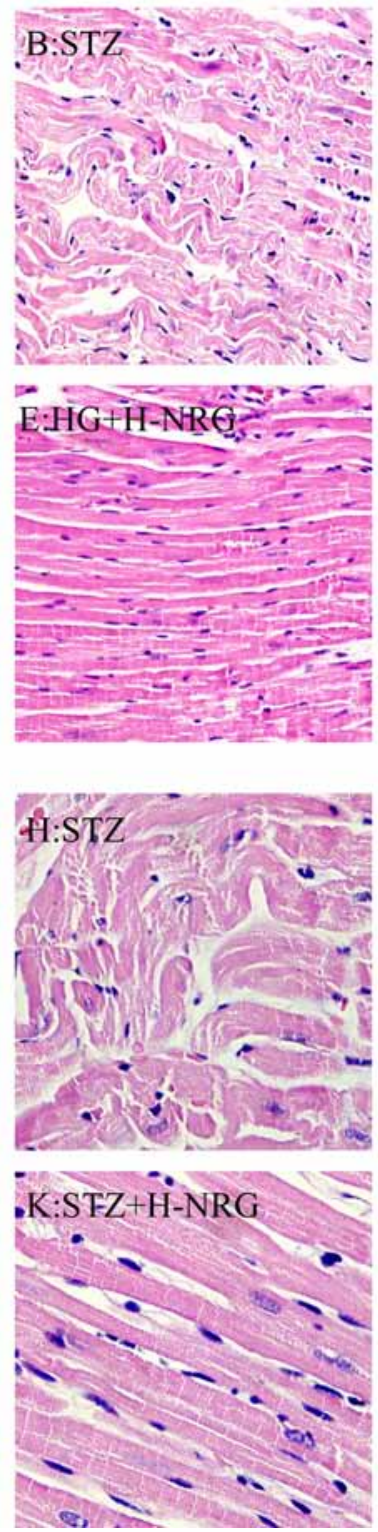
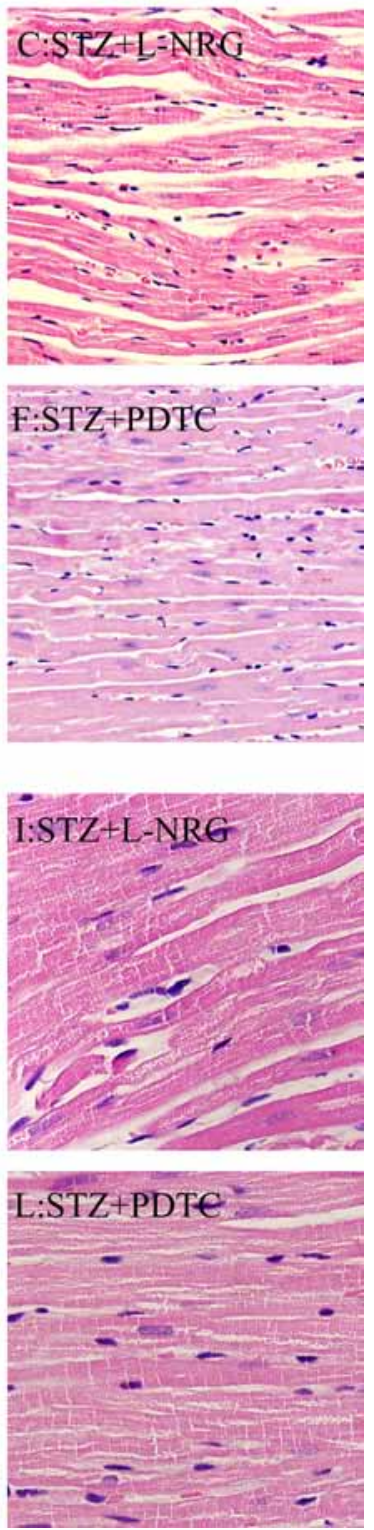

Figure 8

The effects of naringin and PDTC on heart tissues changes of STZ-induced diabetic rats. (200x: A $\rightarrow F, 400 x: G \rightarrow L$ ). A and G: Control group; $\mathrm{B}$ and $\mathrm{H}$ : STZ-induced diabetic rats group; $\mathrm{C}$ and I: STZ + L-NRG group, STZ-induced diabetic rats treatment with low-dose NRG; D and J:

STZ+ M-NRG group, STZ-induced diabetic rats treatment with middle-dose NRG; $\mathrm{E}$ and $\mathrm{K}$ : $\mathrm{STZ}+\mathrm{H}-\mathrm{NRG}$ group, STZ-induced diabetic rats treatment with high-dose NRG; $F$ and L: STZ+ PDTC group, STZ-induced diabetic rats treatment with PDTC. STZ, streptozotocin; NRG, naringin; PDTC, pyrrolidine dithiocarbamate, a specific inhibitor of NF-kB pathway. the expression level of bcl-2 was decreased. However, the increased expression levels of cleaved caspase- 3 and bax were attenuated by pretreatment with $80 \mu \mathrm{M} \mathrm{NRG}$ for $2 \mathrm{~h}$ or $100 \mu \mathrm{M}$ PDTC for $30 \mathrm{~min}$ (STZ + NRG treatment rats or PDTC treatment rats, respectively), and the decreased expression level of bcl-2 was upregulated. Alone, NRG or PDTC did not significantly affect the basal expression level of cleaved caspase-3, bax and bcl-2.

\section{NRG and PDTC diminish HG-induced increased oxidative stress in $\mathrm{H} 9 \mathrm{c} 2$ cardiac cells}

This study demonstrated that oxidative stress contributed to HG-induced cardiomyocyte injury
(Chen et al. 2014a,b). As shown in Fig. 5, exposure of $\mathrm{H} 9 \mathrm{c} 2$ cells to $35 \mathrm{mM}$ glucose for $24 \mathrm{~h}$ markedly induced oxidative stress, as evidenced by an increase in the generation of ROS (Fig. 5A-b and g), a decrease in the SOD activity (Fig. 5B) and an increased expression level of Nox 4 (Fig. 5C). However, pretreatment of the cells with $80 \mu \mathrm{M}$ NRG for $2 \mathrm{~h}$ before HG exposure obviously mitigated the HG-induced increase in ROS generation (Fig. 5A-c and $\mathrm{g})$, increased the HG-induced decrease in SOD activity (Fig. 5B) and decreased the expression level of Nox4 (Fig. 5C). To test whether the NF-кB signaling pathway is involved in $\mathrm{HG}$-induced oxidative stress, H9c2 cells were pretreated with $100 \mu \mathrm{M}$ PDTC for $30 \mathrm{~min}$ before exposure to HG. Our data showed that pretreatment with PDTC

Published by Bioscientifica Ltd 

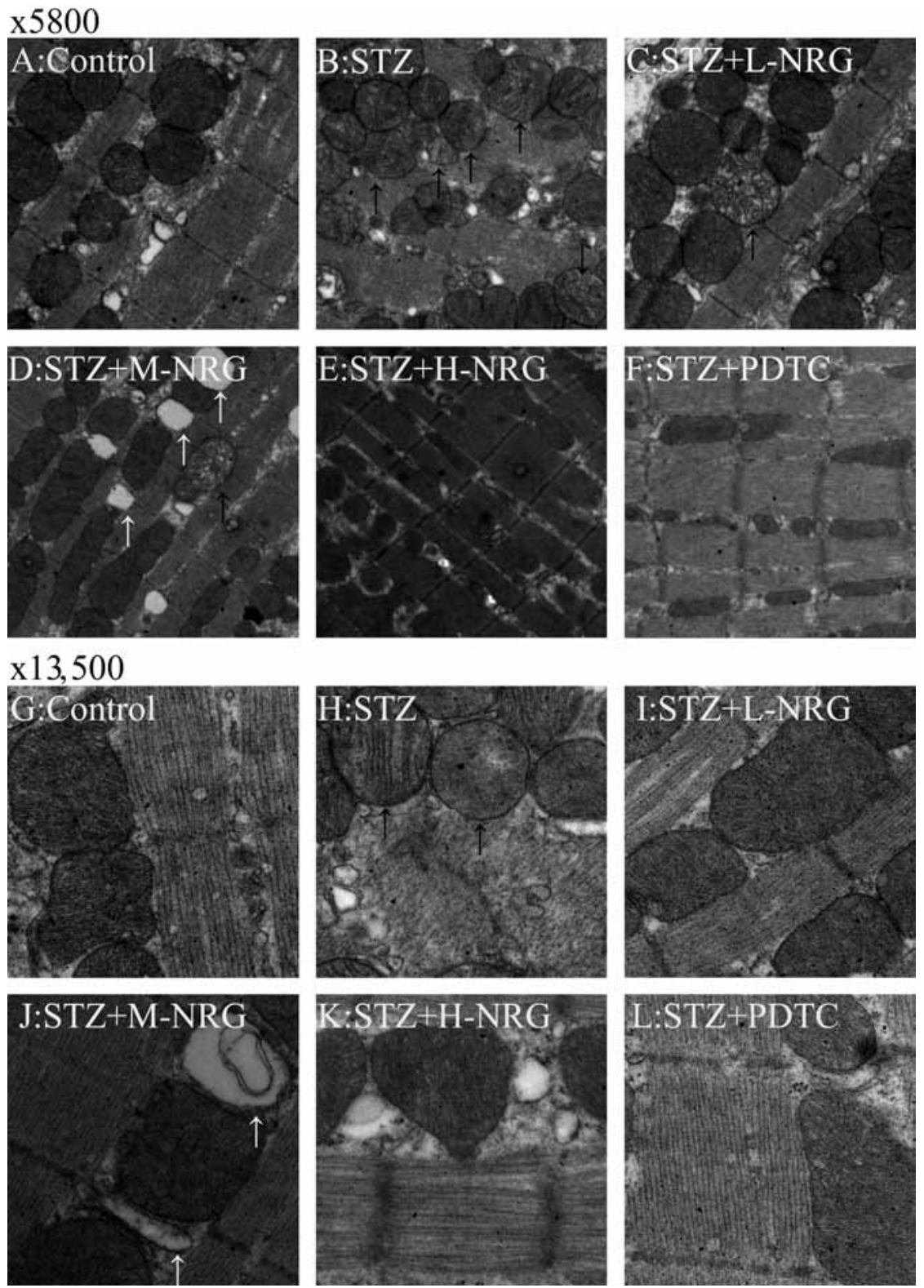

Figure 9

The effects of NRG and PDTC on ultrastructure changes of STZ-induced diabetic rats heart tissues (5800x: A $\rightarrow F, 13,500 x: G \rightarrow L$ ). A and $G$ : Control group; B and H: STZ-induced diabetic rats group; $C$ and I: STZ + L-NRG group, STZ-induced diabetic rats treatment with low-dose NRG; D and J: STZ + M-NRG group, STZ-induced diabetic rats treatment with middle-dose NRG; E and K: STZ + H-NRG group, STZ-induced diabetic rats treatment with high-dose NRG; F and L: STZ + PDTC group, STZ-induced diabetic rats treatment with PDTC. STZ, streptozotocin; NRG, naringin; PDTC, pyrrolidine dithiocarbamate, a specific inhibitor of NF-KB pathway. Black arrow: swollen mitochondria, white arrow: vacuolar mitochondria.

considerably diminished the generation of ROS (Fig. 5A-d and g), upregulated SOD activity (Fig. 5B) and inhibited Nox4 expression (Fig. 5C). NRG or PDTC treatment alone did not change the basal level of ROS, SOD activity and Nox4 expression in H9c2 cells.

\section{NRG and PDTC block the HG-induced dissipation of MMP in H9c2 cells}

As with oxidative stress, mitochondrial damage has been shown to be involved in HG-induced cardiomyocyte injury (Chen et al. 2014a,b, Xu et al. 2015). It was shown that exposure of the cells to $35 \mathrm{mM}$ glucose for $24 \mathrm{~h}$ elicited mitochondrial damage, as manifested by the dissipation of MMP (Fig. 6B and G). The dissipation of MMP was reduced by pretreatment of the cells with $80 \mu \mathrm{M}$ NRG for $2 \mathrm{~h}$ before exposure to HG (Fig. 6C and G), which showed that NRG protected $\mathrm{H} 9 \mathrm{c} 2$ cells against HG-induced mitochondrial damage. Similarly, the pretreatment of cardiomyocytes with $100 \mu \mathrm{M}$ PDTC for $30 \mathrm{~min}$ before exposure to HG similarly attenuated the HG-induced dissipation of MMP (Fig. 6D and G). http://joe.endocrinology-journals.org
DOI: 10.1530/JOE-16-0004
๑ 2016 Society for Endocrinology Printed in Great Britain 
NRG and PDTC suppress the hyperglycemia-induced production of pro-inflammatory cytokines by inhibiting the NF-KB pathway in $\mathrm{H} 9 \mathrm{c} 2$ cardiac cells and in STZ-induced diabetic rats

As shown in Fig. 7, the levels of IL-1 $\beta$ (Fig. 7A and B), IL-6 (Fig. 7C and D) and TNF- $\alpha$ (Fig. 7E and F) were markedly increased in hyperglycemia-induced $\mathrm{H} 9 \mathrm{c} 2$ cardiac cells and in STZ-induced diabetic rats compared with the control group $(P<0.01)$. However, these increased levels of IL-1 $\beta$, IL- 6 and TNF- $\alpha$ were significantly suppressed by treatment with NRG, which suggested an inhibitory effect of NRG on the production of pro-inflammatory cytokines, including IL-1 $\beta$, IL- 6 and TNF- $\alpha$, induced by hyperglycemia. Similarly, the treatment of H9c2 cells with PDTC, a specific inhibitor of the NF- $\mathrm{kB}$ pathway, depressed the enhanced production of IL- $1 \beta$, IL- 6 and TNF- $\alpha$.

\section{The effects of NRG and PDTC on structural changes of the heart tissues of STZ-induced diabetic rats by H\&E staining}

H\&E staining of the heart tissues showed that compared with the control group, diabetic hearts displayed structural abnormalities, such as the degeneration of cardiac myofibrils, a marked separation of myocardial fibers from each other, and hemorrhagic areas (Fig. 8B and $\mathrm{H}$ ). These structural abnormalities in the heart of STZ diabetic animals were at least partially prevented by L-NRG (Fig. 8C and I), M-NRG (Fig. 8D and J), H-NRG (Fig. 8E and K) or PDTC (Fig. 8F and L) treatment.

\section{The effects of NRG and PDTC on ultrastructural changes in the heart tissues of STZ-induced diabetic rats by transmission electron microscopy analysis}

The myocardial structure was examined by transmission electron microscopy. In the control group, well-organized, typical symmetric myofibrils and packed mitochondria beside the fibers were observed, the mitochondria were oval in shape, the ridge was closely spaced with the intact membrane, and the gap junctions were visible and dense. The STZ-induced diabetic rat heart tissues showed loss and damage of myofibrils compared with the control group, along with a significantly decreased volume of myofibrils. As shown in Fig. 9B, the mitochondria were swollen, fragmented, distended and clumped, and the cristae in the mitochondria were distorted or completely lysed. In addition, some disks were distorted and ruptured. After treatment with $25 \mathrm{mg} / \mathrm{kg} /$ day NRG (low-dose NRG) (Fig. 9C and L), $50 \mathrm{mg} / \mathrm{kg} /$ day NRG (middle-dose NRG) (Fig. 9D and J), $100 \mathrm{mg} / \mathrm{kg} /$ day NRG (high-dose NRG) (Fig. 9E and $\mathrm{K}$ ) or $100 \mathrm{mg} / \mathrm{kg} /$ day PDTC (Fig. 9D), the STZ-induced diabetic rats exhibited improved cardiac structure. The damage to myofibrils was reversed, and the volume percentage of myofibrils was increased. The swelling, fragmentation, distension and clumping of mitochondria were suppressed, and the number of STZ-induced injuries in mitochondria was also decreased. There was limited rupture or dissolution of the fibrin in the sarcomere, and the cross-connections of the intercalated disk were also clear.

\section{Discussion}

In this study, we demonstrate that the NF- $\mathrm{kB}$ pathway, which regulates cardiac cell apoptosis, oxidative stress, mitochondrial damage, the production of pro-inflammatory cytokines, myocardial hypertrophy, myocardial remodeling and cardiac fibrosis in DM, is a crucial regulatory mechanism for the development of DCM. Otherwise, $\mathrm{K}_{\text {ATP }}$ has an important role in the HG-induced injury of $\mathrm{H} 9 \mathrm{c} 2$ cardiac cells. More importantly, we provide new insight into the mechanisms responsible for the cardioprotection of NRG against hyperglycemia-induced cardiac cell injuries by inhibiting the activation of NF-кB pathway in vitro and in vivo and upregulating $\mathrm{K}_{\mathrm{ATP}}$ channels in vitro.

In this study, p65 was our target to test the effect of the NF-кB pathway in STZ-induced diabetic rats and in HG-induced injuries to H9c2 cardiac cells. Similar to previous studies (Valen et al. 2001, Fang et al. 2004, Eisner et al. 2006, Westermann et al. 2007a,b, Mariappan et al. 2010, Arkan \& Greten 2011), our findings showed that hyperglycemia could increase the expression level of p-NF-kB p65 (Fig. 1). Furthermore, NF-kB was activated and dissociated from I $\mathrm{KB}$ and released and translocated into the nucleus from the cytoplasm, which led to an increase in the expression level of nuclear (nuc) p65 (Fig. 1). This allowed NF- $\mathrm{kB}$ (p65) to bind to $\kappa \mathrm{B}$ sequences in DNA and alter the expression of various target genes (Rajadurai $\&$ Prince 2009). These results strongly indicated that the NF-kB pathway was activated and might be involved in the pathogenesis of DCM. In our present research, we found that the NF-kB pathway was involved in hyperglycemiainduced cytotoxicity (Fig. 3A), apoptosis (Fig. 4), oxidative stress (Fig. 5), dissipation of MMP (Fig. 6), inflammation (Fig. 7) and myocardial remodeling (Figs 8 and 9). These findings demonstrated that the activation of

Published by Bioscientifica Ltd. 
NF-kB plays a crucial role in the development of DCM in diabetic patients by controlling different set of genes and participating in the related processes. Moreover, cardiac $\mathrm{K}_{\mathrm{ATP}}$ channels are very important for the metabolic status of cardiomyocytes as key sensors and effectors, and their roles in the HG-induced cardiomyocyte injury have conspicuously attracted attention. First, in this study, our data showed that exposure of the cardiac cells to HG prominently reduced the expression level of $\mathrm{K}_{\text {ATP }}$ channels, which suggested that $\mathrm{K}_{\mathrm{ATP}}$ channels may be involved in the progress of HG-induced cardiac cell injuries. A recent study indicated that a reduction in number of sarcolemmal $\mathrm{K}_{\text {ATP }}$ channels affects cardiac action potentials under hypoxia (Zhu et al. 2011); therefore, we hypothesized that the inhibition of cardiac $K_{A T P}$ channels might be a pivotal mechanism underlying HG-induced cardiomyocyte injury. To confirm our hypothesis, we secondarily observed the influence of $\mathrm{K}_{\mathrm{ATP}}$ channel activation on HG-induced injury. In agreement with our recent studies (Zhu et al. 2011, Chen et al. 2014a,b), the findings of this study showed that treatment of $\mathrm{H} 9 \mathrm{c} 2$ cardiac cells with HG induced considerable injuries, including a decrease in cell viability. However, pretreatment of $\mathrm{H} 9 \mathrm{c} 2$ cardiac cells with DZ or Pin markedly attenuated the HG-induced injuries, as evidenced by an increase in cell viability. The above results suggest that $\mathrm{HG}$ impairs the function of cardiac $\mathrm{K}_{\mathrm{ATP}}$ channels, which contributes to HG-induced injuries. Thus, the above results strongly suggested that NF-KB and $\mathrm{K}_{\mathrm{ATP}}$ channels might play critical roles in the pathogenesis of DCM.

An important finding of this study relates to the cardioprotection of NRG in hyperglycemia-induced insults in vitro and in vivo. First, consistent with the previously reported results (Huang et al. 2013), we found that NRG markedly suppressed HG-triggered cytotoxicity and apoptosis, and it was suggested that NRG contributed to cardioprotection by attenuating mitochondrial dysfunction and inhibiting the activation of the p38 MAPK pathway. Our results are supported by a series of previous studies (Jagetia et al. 2003, Kanno et al. 2003, 2004, Wu et al. 2013). Second, we observed that NRG could exert remarkable antihyperglycemic effects (Table 1) in STZ-induced diabetic rats. Its mechanism has multiple components: (i) NRG activates glutathione (GSH) synthesis through a novel antioxidant defense mechanism against excessive ROS production, which contributes to the prevention of oxidative damage in addition to its effect on glycemic control (Dhanya et al. 2015); (ii) NRG plays important roles in preventing the progression of hyperglycemia, partly by binding to starch by increasing hepatic glycolysis and the glycogen concentration and lowering hepatic gluconeogenesis (Shen et al. 2012); (iii) NRG exhibits antidiabetic effects in a rat model of type 2 diabetes mellitus (T2DM) by potentiating the antioxidant defense system and suppressing pro-inflammatory cytokine production (Mahmoud et al. 2012). Third, this study demonstrates the inhibitory effect of NRG on myocardial remodeling and cardiac fibrosis in STZinduced diabetic rats by inhibiting the NF- $\mathrm{kB}$ pathway. Fourth, our study shows the inhibitory effect of NRG on hyperglycemia-induced NF-kB activation. Currently, the effects of NRG against hyperglycemia-induced cardiac injury in DM have attracted considerable attention due to its cardioprotective effect (Kanno et al. 2004, Rajadurai \& Prince 2007, 2009). Our more recent study showed that NRG could protect cardiomyocytes against HG-induced injuries by inhibiting the activation of MAPKs (Jung et al. 2003) and the leptin-p38 MAPK (Chen et al. 2014a,b) pathway in H9c2 cells. However, the mechanisms underlying the effect of NRG on the NF-kB pathway remain unclear. Thus, this study explored the effect of NRG on the activation of the NF-кB pathway in HG-treated H9c2 cardiac cells and in STZ-induced diabetic rats. As in our previous study (Wu et al. 2013), NRG considerably suppressed the expression levels of p-p65, which suggested that NRG could inhibit the hyperglycemia-induced activation of NF- $\mathrm{KB}$ in vitro and in vivo. These results suggested that the NF-кB pathway might play a critical role in the cardioprotection of NRG.

However, the protective mechanisms of NRG are complicated, and other factors may also be involved in the cardioprotection of NRG. Interestingly, the results of this study relate to the role of the activation of $\mathrm{K}_{\text {ATP }}$ channels in the cardioprotective effects of NRG against HG-induced cardiac injuries. Our results demonstrated that NRG markedly reduced the downregulation of $\mathrm{K}_{\text {ATP }}$ channel expression by HG and that both 5-HD and Gli significantly blocked the cardioprotective effect of NRG mentioned above. These results suggested that $\mathrm{K}_{\mathrm{ATP}}$ channels, particularly the mitochondrial $\mathrm{K}_{\mathrm{ATP}}$ channels, might play a critical role in the cardioprotection of NRG.

In this study, we also investigated the relationship between the NF- $\mathrm{kB}$ pathway and cardiac $\mathrm{K}_{\mathrm{ATP}}$ channel activation. As mentioned above, PDTC, an inhibitor of the NF-kB pathway, markedly blocked a decrease in the expression of $\mathrm{K}_{\text {ATP }}$ channel proteins induced by HG. Collectively, these results revealed that $\mathrm{K}_{\mathrm{ATP}}$ channels might be a downstream molecule of the NF- $\mathrm{kB}$ pathway in HG-treated cardiac cells. Elucidating the molecular mechanism underlying this interaction may be significant in the treatment and prevention of DM-related DCM.

Published by Bioscientifica Ltd 
Exposing H9c2 cells to $\mathrm{HG}$ for $12 \mathrm{~h}$ markedly decreased the expression level of $\mathrm{K}_{\text {ATP }}$ channel proteins and increased the ADP/ATP ratio. An increase in the ATP/ADP ratio closes $K_{\text {ATP }}$ channels (which leads to depolarization), whereas a decrease in the ATP/ADP ratio opens $\mathrm{K}_{\mathrm{ATP}}$ channels (which leads to hyperpolarization) (Sun \& Feng 2013). These changes suggest that HG both opened and inhibited the expression level of $\mathrm{K}_{\text {ATP }}$ channels. It is difficult to explain this phenomenon. Its potential mechanism requires further research.

Therefore, the above findings showed that the activation of NF- $\mathrm{KB}$ is involved in hyperglycemia-induced cytotoxicity, apoptosis, ROS production, the dissipation of MMP, myocardial remodeling and myocardial fibrosis in vitro and in vivo. HG impairs the function of cardiac $\mathrm{K}_{\text {ATP }}$ channels, which contribute to HG-induced injuries. Our results revealed that the inhibitory effect of NRG on the activation of NF- $\mathrm{KB}$ might be one of the important mechanisms responsible for its protection against hyperglycemia-induced injuries in $\mathrm{H} 9 \mathrm{c} 2$ cardiac cells and in STZ-induced type 2 diabetic rats.

\section{Conclusions}

In conclusion, our study demonstrated that NRG, which could protect cardiomyocytes against hyperglycemiainduced injury in vivo and in vitro, had antimitochondrial, anti-oxidant, anti-apoptosis, anti-inflammatory and antifibrosis activities at least partially by inhibiting the NF- $\mathrm{B}$ pathway and upregulating $\mathrm{K}_{\mathrm{ATP}}$ channels. These results also raise the possibility that NRG may be a potential candidate in the prevention and treatment of diabetic vascular complications at an appropriate dosage.

\section{Declaration of interest}

The authors declare that there is no conflict of interest that could be perceived as prejudicing the impartiality of the research reported.

\section{Funding}

This study was supported by grants from the Science and Technology Planning Project of Guangdong in China (no. 2012A080202020) and the Guangdong Natural Science Foundation (no. S2011010002620).

\section{References}

Arkan MC \& Greten FR 2011 IKK- and NF-кB-mediated functions in carcinogenesis. Current Topics in Microbiology and Immunology 349 159-169.
Badalzadeh R, Yousefi B, Majidinia M \& Ebrahimi H 2014 Anti-arrhythmic effect of diosgenin in reperfusion-induced myocardial injury in a rat model: activation of nitric oxide system and mitochondrial KATP channel. Journal of Physiological Sciences 64 393-400. (doi:10.1007/s12576-014-0333-8)

Badalzadeh R, Yousefi B, Tajaddini A \& Ahmadian N 2015 Diosgenininduced protection against myocardial ischaemia-reperfusion injury is mediated by mitochondrial KATP channels in a rat model. Perfusion 30 565-571. (doi:10.1177/0267659114566064)

Bodas R, Prieto N, López-Campos O, Giráldez FJ \& Andrés S 2011 Naringin and vitamin E influence the oxidative stability and lipid profile of plasma in lambs fed fish oil. Research in Veterinary Science $\mathbf{9 1}$ 98-102. (doi:10.1016/j.rvsc.2010.07.028)

Boudina S, Sena S, Theobald H, Sheng X, Wright JJ, Hu XX, Aziz S, Johnson JI, Bugger H, Zaha VG, et al. 2007 Mitochondrial energetics in the heart in obesity-related diabetes: direct evidence for increased uncoupled respiration and activation of uncoupling proteins. Diabetes 56 2457-2466. (doi:10.2337/db07-0481)

Camafort M 2015 What's new in heart failure in the patient with type 2 diabetes? Endocrinología y Nutrición 62 350-355. (doi:10.1016/ j.endonu.2015.06.004)

Ceriello A 2008 Cardiovascular effects of acute hyperglycemia: pathophysiological underpinnings. Diabetes \& Vascular Disease Research 5 260-268. (doi:10.3132/dvdr.2008.038)

Chen SH, Khan ZA, Cukiernik M \& Chakrabarti S 2003 Differential activation of NF-kappa B and AP-1 in increased fibronectin synthesis in target organs of diabetic complications. American Journal of Physiology: Endocrinology and Metabolism 284 E1089-E1097.

Chen J, Guo R, Yan H, Tian L, You Q, Li S, Huang R \& Wu K $2014 a$ Naringin inhibits ROS-activated MAPK pathway in high glucoseinduced injuries in H9c2 cardiac cells. Basic and Clinical Pharmacology and Toxicology 114 293-304.

Chen J, Mo H, Guo R, You Q, Huang R \& Wu K 2014b Inhibition of the leptin-induced activation of the p38 MAPK pathway contributes to the protective effects of naringin against high glucose-induced injury in $\mathrm{H} 9 \mathrm{c} 2$ cardiac cells. International Journal of Molecular Medicine $\mathbf{3 3}$ 605-612.

Dhanya R, Arun KB, Nisha VM, Syama HP, Nisha P, Santhosh Kumar TR \& Jayamurthy P 2015 Preconditioning L6 muscle cells with naringin ameliorates oxidative stress and increases glucose uptake. PLoS ONE 10 e 0132429.

Di Filippo C, Marfella R, Cuzzocrea S, Piegari E, Petronella P, Giugliano D, Rossi F \& D'Amico M 2005 Hyperglycemia in streptozotocin-induced diabetic rat increases infarct size associated with low levels of myocardial HO-1 during ischemia/reperfusion. Diabetes 54 803-810. (doi:10.2337/diabetes.54.3.803)

Eisner V, Criollo A, Quiroga C, Olea-Azar C, Santibañez JF, Troncoso R, Chiong M, Díaz-Araya G, Foncea R \& Lavandero S 2006 Hyperosmotic stress-dependent NFkappaB activation is regulated by reactive oxygen species and IGF-1 in cultured cardiomyocytes. FEBS Letters $\mathbf{5 8 0}$ 4495-4500. (doi:10.1016/j.febslet.2006.07.029)

Ellis CR \& Di Salvo T 2007 Myocarditis: basic and clinical aspects. Cardiology in Review 15 170-177. (doi:10.1097/ CRD.0b013e31806450c4)

Fancher IS, Dick GM \& Hollander JM 2013 Diabetes mellitus reduces the function and expression of ATP-dependent $\mathrm{K}^{+}$channels in cardiac mitochondria. Life Sciences 92 664-668. (doi:10.1016/ j.lfs.2012.11.019)

Fang ZY, Prins JB \& Marwick TH 2004 Diabetic cardiomyopathy: evidence, mechanisms, and therapeutic implications. Endocrine Reviews 25 543-567. (doi:10.1210/er.2003-0012)

Fonarow GC \& Srikanthan P 2006 Diabetic cardiomyopathy. Endocrinology and Metabolism Clinics of North America 35 575-599. (doi:10.1016/j.ecl.2006.05.003)

Guleria RS, Singh AB, Nizamutdinova IT, Souslova T, Mohammad AA, Kendall JA Jr, Baker KM \& Pan J 2013 Activation of retinoid 
receptor-mediated signaling ameliorates diabetes-induced cardiac dysfunction in Zucker diabetic rats. Journal of Molecular and Cellular Cardiology 57 106-118. (doi:10.1016/j.yjmcc.2013.01.017)

Huang ES, Basu A, O'Grady M \& Capretta JC 2009 Projecting the future diabetes population size and related costs for the U.S. Diabetes Care 32 2225-2229.

Huang H, Wu K, You Q, Huang R, Li S \& Wu K 2013 Naringin inhibits high glucose-induced cardiomyocyte apoptosis by attenuating mitochondrial dysfunction and modulating the activation of the p38 signaling pathway. International Journal of Molecular Medicine 32 396-402.

Jagetia GC, Venkatesha VA \& Reddy TK 2003 Naringin, a citrus flavonone, protects against radiation-induced chromosome damage in mouse bone marrow. Mutagenesis 18 337-343. (doi:10.1093/ mutage/geg001)

Jain M \& Parmar HS 2011 Evaluation of antioxidative and antiinflammatory potential of hesperidin and naringin on the rat air pouch model of inflammation. Inflammation Research 60 483-491. (doi:10.1007/s00011-010-0295-0)

Jeon SM, Park YB \& Choi MS 2004 Antihypercholesterolemic property of naringin alters plasma and tissue lipids, cholesterol-regulating enzymes, fecal sterol and tissue morphology in rabbits. Clinical Nutrition 23 1025-1034. (doi:10.1016/j.clnu.2004.01.006)

Jung UJ, Kim HJ, Lee JS, Lee MK, Kim HO, Park EJ, Kim HK, Jeong TS \& Choi MS 2003 Naringin supplementation lowers plasma lipids and enhances erythrocyte antioxidant enzyme activities in hypercholesterolemic subjects. Clinical Nutrition 22 561-568. (doi:10.1016/S0261-5614(03)00059-1)

Jung UJ, Lee MK, Park YB, Kang MA \& Choi MS 2006 Effect of citrus flavonoids on lipid metabolism and glucose-regulating enzyme mRNA levels in type-2 diabetic mice. International Journal of Biochemistry and Cell Biology 38 1134-1145. (doi:10.1016/j.biocel.2005.12.002)

Kamalakkannan N \& Prince PS 2006 Anti-hyperglycemic and antioxidan effect of rutin, a polyphenolic flavonoid, in streptozotocin-induced diabetic wistar rats. Basic and Clinical Pharmacology and Toxicology 98 97-103. (doi:10.1111/j.1742-7843.2006.pto_241.x)

Kanno S, Shouji A, Asou K \& Ishikawa M 2003 Effects of naringin on hydrogen peroxide-induced cytotoxicity and apoptosis in P388 cells. Journal of Pharmacological Sciences 92 166-170. (doi:10.1254/ jphs.92.166)

Kanno S, Shouji A, Hirata R, Asou K \& Ishikawa M 2004 Effects of naringin on cytosine arabinoside (Ara-C)-induced cytotoxicity and apoptosis in P388 cells. Life Sciences 75 353-365. (doi:10.1016/j. lfs.2003.12.019)

Kim HJ, Oh GT, Park YB, Lee MK, Seo HJ \& Choi MS 2004 Naringin alters the cholesterol biosynthesis and antioxidant enzyme activities in LDL receptor-knockout mice under cholesterol fed condition. Life Sciences 74 1621-1634. (doi:10.1016/j.lfs.2003.08.026)

Kinoshita H, Azma T, Nakahata K, Iranami H, Kimoto Y, Dojo M, Yuge O \& Hatano Y 2004 Inhibitory effect of high concentration of glucose on relaxations to activation of ATP-sensitive $\mathrm{K}+$ channels in human omental artery. Arteriosclerosis, Thrombosis, and Vascular Biology 24 2290-2295. (doi:10.1161/01.ATV.0000148006.78179.c7)

Kinoshita H, Azma T, Iranami H, Nakahata K, Kimoto Y, Dojo M, Yuge O \& Hatano Y 2006 Synthetic peroxisome proliferator-activated receptor-gamma agonists restore impaired vasorelaxation via ATPsensitive $\mathrm{K}+$ channels by high glucose. Journal of Pharmacology and Experimental Therapeutics 318 312-318. (doi:10.1124/jpet.106.100958)

Lakdawala NK, Winterfield JR \& Funke BH 2013 Dilated cardiomyopathy. Circulation Arrhythmia and Electrophysiology 6 228-237. (doi:10.1161/ CIRCEP.111.962050)

Mahmoud AM, Ashour MB, Abdel-Moneim A \& Ahmed OM 2012 Hesperidin and naringin attenuate hyperglycemia-mediated oxidative stress and proinflammatory cytokine production in high fat fed/ streptozotocin-induced type 2 diabetic rats. Journal of Diabetes and its Complications 26 483-490. (doi:10.1016/j.jdiacomp.2012.06.001)

http://joe.endocrinology-journals.org

DOI: $10.1530 / J O E-16-0004$
๑) 2016 Society for Endocrinology Printed in Great Britain
Marfella R, Siniscalchi M, Esposito K, Sellitto A, De Fanis U, Romano C, Portoghese M, Siciliano S, Nappo F, Sasso FC, et al. 2003 Effects of stress hyperglycemia on acute myocardial infarction: role of inflammatory immune process in functional cardiac outcome. Diabetes Care 26 3129-3135. (doi:10.2337/diacare.26.11.3129)

Mariappan N, Elks CM, Sriramula S, Guggilam A, Liu Z, Borkhsenious O \& Francis J 2010 NF-kappaB-induced oxidative stress contributes to mitochondrial and cardiac dysfunction in type II diabetes. Cardiovascular Research 85 473-483. (doi:10.1093/cvr/cvp305)

Min W, Bin ZW, Quan ZB, Hui ZJ \& Sheng FG 2009 The signal transduction pathway of PKC/NF-kappa B/c-fos may be involved in the influence of high glucose on the cardiomyocytes of neonatal rats. Cardiovascular Diabetology 8 8-8. (doi:10.1186/1475-2840-8-8)

Miura H, Wachtel RE, Loberiza FR Jr, Saito T, Miura M, Nicolosi AC \& Gutterman DD 2003 Diabetes mellitus impairs vasodilation to hypoxia in human coronary arterioles: reduced activity of ATPsensitive potassium channels. Circulation Research 92 151-158. (doi:10.1161/01.RES.0000052671.53256.49)

Murali R, Karthikeyan A \& Saravanan R 2013 Protective effects of D-limonene on lipid peroxidation and antioxidant enzymes in streptozotocin-induced diabetic rats. Basic and Clinical Pharmacology and Toxicology 112 175-181. (doi:10.1111/bcpt.12010)

Peake BF, Nicholson CK, Lambert JP, Hood RL, Amin H, Amin S \& Calvert JW 2013 Hydrogen sulfide preconditions the $\mathrm{db} / \mathrm{db}$ diabetic mouse heart against ischemia-reperfusion injury by activating Nrf2 signaling in an Erk-dependent manner. American Journal of Physiology: Heart and Circulatory Physiology 304 H1215-H1224.

Privratsky JR, Wold LE, Sowers JR, Quinn MT \& Ren J 2003 AT1 blockade prevents glucose-induced cardiac dysfunction in ventricular myocytes: role of the AT1 receptor and NADPH oxidase. Hypertension 42 206-212. (doi:10.1161/01.HYP.0000082814.62655.85)

Rajadurai M \& Prince PS 2007 Preventive effect of naringin on isoproterenol-induced cardiotoxicity in Wistar rats: an in vivo and in vitro study. Toxicology 232 216-225. (doi:10.1016/j.tox.2007.01.006)

Rajadurai M \& Prince PS 2009 Naringin ameliorates mitochondrial lipid peroxides, antioxidants and lipids in isoproterenol-induced myocardial infarction in Wistar rats. Phytotherapy Research 23 358-362. (doi:10.1002/ptr.2632)

Saandeep K, Vikram A, Tripathi DN, Ramarao P \& Jena G 2009 Influence of hyperglycemia on chemical-induced toxicity: study with cyclophosphamide in rat. Basic and Clinical Pharmacology and Toxicology 105 236-242. (doi:10.1111/j.1742-7843.2009.00433.x)

Shen W, Xu Y \& Lu YH 2012 Inhibitory effects of Citrus flavonoids on starch digestion and antihyperglycemic effects in HepG2 cells. Journal of Agricultural and Food Chemistry 60 9609-9619. (doi:10.1021/ jf3032556)

Sun HS \& Feng ZP 2013 Neuroprotective role of ATP-sensitive potassium channels in cerebral ischemia. Acta Pharmaceutica Sinica 34 24-32. (doi:10.1038/aps.2012.138)

Tsai KH, Wang WJ, Lin CW, Pai P, Lai TY, Tsai CY \& Kuo WW 2012 NADPH oxidase-derived superoxide anion-induced apoptosis is mediated via the JNK-dependent activation of NF- $\kappa \mathrm{B}$ in cardiomyocytes exposed to high glucose. Journal of Cellular Physiology 227 1347-1357. (doi:10.1002/jcp.22847)

Umbarkar P, Singh S, Arkat S, Bodhankar SL, Lohidasan S \& Sitasawad SL 2015 Monoamine oxidase-A (MAO-A) is an important source of oxidative stress and promotes cardiac dysfunction, apoptosis, and fibrosis in diabetic cardiomyopathy. Free Radical Biology and Medicine 87 263-273. (doi:10.1016/j.freeradbiomed.2015.06.025)

Valen G, Yan ZQ \& Hansson GK 2001 Nuclear factor kappa-B and the heart. Journal of the American College of Cardiology 38 307-314. (doi:10.1016/S0735-1097(01)01377-8)

van Heerebeek L, Hamdani N, Handoko ML, Falcao-Pires I, Musters RJ, Kupreishvili K, Ijsselmuiden AJ, Schalkwijk CG, Bronzwaer JG, Diamant M, et al. 2008 Diastolic stiffness of the failing diabetic heart: importance of fibrosis, advanced 
glycation end products, and myocyte resting tension. Circulation 117 43-51. (doi:10.1161/CIRCULATIONAHA. 107.728550)

Venkatachalam K, Mummidi S, Cortez DM, Prabhu SD, Valente AJ \& Chandrasekar B 2008 Resveratrol inhibits high glucose-induced PI3K/ Akt/ERK-dependent interleukin-17 expression in primary mouse cardiac fibroblasts. American Journal of Physiology: Heart and Circulatory Physiology 294 H2078-H2087. (doi:10.1152/ajpheart.01363.2007)

Waza AA, Andrabi K \& Hussain MU 2014 Protein kinase C (PKC) mediated interaction between conexin $43(\mathrm{Cx} 43)$ and $\mathrm{K}(+)$ (ATP) channel subunit (Kir6.1) in cardiomyocyte mitochondria: Implications in cytoprotection against hypoxia induced cell apoptosis. Cellular Signalling 26 1909-1917. (doi:10.1016/ j.cellsig.2014.05.002)

Weintraub NL 2003 Impaired hypoxic coronary vasodilation and ATPsensitive potassium channel function: a manifestation of diabetic microangiopathy in humans? Circulation Research 92 127-129. (doi:10.1161/01.RES.0000056965.71699.02)

Werner SL, Barken D \& Hoffmann A 2005 HStimulus specificity of gene expression programs determined by temporal control of IKK activity. Science 309 1857-1861. (doi:10.1126/science.1113319)

Westermann D, Rutschow S, Jäger S, Linderer A, Anker S, Riad A, Unger T, Schultheiss HP, Pauschinger M \& Tschöpe C 2007a Contributions of inflammation and cardiac matrix metalloproteinase activity to cardiac failure in diabetic cardiomyopathy: the role of angiotensin type 1 receptor antagonism. Diabetes 56 641-646.

Westermann D, Van Linthout S, Dhayat S, Dhayat N, Escher F, Bücker-Gärtner C, Spillmann F, Noutsias M, Riad A, Schultheiss HP, et al. $2007 \mathrm{~b}$ Cardioprotective and anti-inflammatory effects of interleukin converting enzyme inhibition in experimental diabetic cardiomyopathy. Diabetes 56 1834-1841.

Wu K, You Q \& Tu YM 2013 Influence of naringin on the myocardial ultrastructure and NF-kB expression in rats with diabetic cardiomyopathy. African Journal of Pharmacy and Pharmacology $\mathbf{7}$ 439-443. (doi:10.5897/AJPP)

Xu W, Chen J, Lin J, Liu D, Mo L, Pan W, Feng J, Wu W \& Zheng D 2015 Exogenous $\mathrm{H}_{2} \mathrm{~S}$ protects $\mathrm{H} 9 \mathrm{c} 2$ cardiac cells against high glucoseinduced injury and inflammation by inhibiting the activation of the $\mathrm{NF}-\mathrm{KB}$ and IL-1 $\beta$ pathways. International Journal of Molecular Medicine 35 177-186.

Zhu Z, Burnett CM, Maksymov G, Stepniak E, Sierra A, Subbotina E, Anderson ME, Coetzee WA, Hodgson-Zingman DM \& Zingman LV 2011 Reduction in number of sarcolemmal KATP channels slows cardiac action potential duration shortening under hypoxia. Biochemical and Biophysical Research Communications 415 637-641. (doi:10.1016/j.bbrc.2011.10.125)

Received in final form 12 May 2016

Accepted 3 June 2016

Accepted Preprint published online 7 June 2016
(C) 2016 Society for Endocrinology Printed in Great Britain
Published by Bioscientifica Ltd 